\title{
Gestión de la internacionalización en la Universidad de Costa Rica y su vínculo con Centroamérica y el Caribe
}

\author{
Management of internationalization at the University of Costa Rica \\ and its relation to Central America and the Caribbean
}

Recibido 09 febrero 2015 • Aceptado 02 junio 2015 • Corregido 12 junio 2015

\author{
Yorleni Aguilar-Castillo ${ }^{7}$ \\ Universidad de Costa Rica \\ Oficina de Asuntos Internacionales \\ y Cooperación Externa \\ San José, Costa Rica \\ yorleni.aguilar@ucr.ac.cr \\ Alba Stella Riveros-Angarita ${ }^{2}$ \\ Asesora y Consultora Externa \\ San José, Costa Rica \\ sriver07@gmail.com
}

\begin{abstract}
Resumen. Este artículo presenta resultados de una investigación cuyo objetivo general fue analizar la gestión de las acciones de internacionalización y cooperación académica de la Universidad de Costa Rica (UCR), durante el periodo 2003-2011, con instituciones de educación superior de Centroamérica y el Caribe. Se trata de un estudio exploratorio y descriptivo, basado en técnicas de investigación cualitativas. La metodología y técnicas de recolección de la información utilizan instrumentos tales como entrevistas, fuentes bibliográficas: documentales y electrónicas. El análisis de datos se presentan según las categorías que apoyaron el estudio: convenios de cooperación, movilidad académica y estudiantil, investigación, reconocimientos y experiencias exitosas en unidades académicas de la UCR. Entre los principales hallazgos resaltan: el conocimiento de la dinámica de internacionalización en doble vía; logros y limitaciones relevantes encontradas en el proceso y la identificación de buenas prácticas. Las vinculaciones de cooperación regional de la UCR han fortalecido de manera importante tanto las carreras de grado como los programas de posgrado. El estudio revela estrategias que han contribuido a mejorar la integración de la internacionalización de la educación superior de UCR respecto a Centroamérica y la región del Caribe.
\end{abstract}

Palabras claves. Administración de la educación superior; contexto regional; cooperación internacional; internacionalización; Centroamérica y Caribe

1 Se desempeña como jefa de la Sección de Cooperación Internacional de la Oficina de Asuntos Internacionales y Cooperación Externa, Universidad de Costa Rica.

2 Asesora, consultora y evaluadora externa en Acreditación y Administración Universitaria para América Latina.

\section{(c) $10(9)$




\begin{abstract}
This article presents the results of a research whose general objective was to analyze the administration of the internationalization activities and academic cooperation at the University of Costa Rica during the period 2003-2011, with higher education institutions of Central America and the Caribbean. It is an exploratory and descriptive study, based on qualitative research techniques. The methodology and techniques of information collection include instruments, such as interviews, and documentary and digital bibliographic material. Data analysis is presented by categories that supported the study: cooperation agreements, academic and students' mobility, research, awards and successful experiences in academic units of UCR schools. Main findings of this study include: knowledge of internationalization dynamics on a two-way basis; relevant outcomes and limitations found in the process and identification of good practices. The regional cooperation linkages of UCR have strengthened significantly undergraduate and graduate programs. The study reveals strategies that have contributed to improve the integration higher education internationalization of UCR on Central America and the Caribbean Region.
\end{abstract}

Keywords. Administration of higher education; regional context; international cooperation; internationalization; Central America and the Caribbean

\title{
Introducción
}

La Universidad de Costa Rica (UCR) consagra sus esfuerzos en ofrecer una educación de calidad, con el fin de optimizar sinergias articulando adecuadamente las funciones sustantivas: docencia, investigación y acción social. Desde sus orígenes, en 1940, ha tenido como visión no solo formar personas en una disciplina en particular, sino además, formar profesionales con capacidad de enfrentar de manera crítica las necesidades de la sociedad costarricense, potenciar su liderazgo en el desarrollo de la educación nacional y atender los cambios a los que están expuestos en el ámbito regional e internacional.

En términos de la internacionalización como eje transversal de las actividades sustantivas, la UCR cuenta con políticas implementadas con el apoyo de la Oficina de Asuntos Internacionales y Cooperación Externa (OAICE), instancia adscrita a la Rectoría, que trabaja en estrecha coordinación con las Vicerrectorías de Docencia, Investigación, Vida Estudiantil y Acción Social, el Sistema de Estudios de Posgrado, Unidades Académicas y de Investigación.

La presente investigación ha tenido como objetivo efectuar un diagnóstico de las principales acciones de internacionalización y cooperación académica internacional desarrolladas entre la UCR y las Instituciones de Educación Superior (IES) de Centroamérica y Caribe en el período 2003-2011, con el fin de proponer estrategias que contribuyan a la integración de la internacionalización en el ambiente regional. 


\section{Justificación del problema y su alcance}

Partiendo de la perspectiva histórica donde pares académicos y estudiantes universitarios interactúan permanentemente entre sí, atravesando fronteras en diversas latitudes en busca del conocimiento, se puede evidenciar que la universidad actual mantiene vigente la condición internacionalista que se dio en sus comienzos.

Según describe Gacel-Ávila (2000), desde la Edad Media hasta avanzado el siglo XX, las relaciones internacionales entre las universidades se desarrollan como parte de su orientación universal. Estas relaciones permiten ampliar la influencia de los países centrales a aquellos periféricos, de manera que cumplen propósitos ideológicos.

En las primeras décadas del siglo XX, las actividades internacionales que realizan las instituciones son de carácter aislado y responden a necesidades institucionales de creación de programas de estudio e intereses de formación individualizada. No existen en esta época tampoco las facilidades de movilidad y contactos que facilitaran una mayor interacción.

Desde mediados del siglo XX, particularmente después de la Segunda Guerra Mundial, las actividades de internacionalización de las universidades estuvieron muy ligadas a visitas espontáneas de docentes y estudiantes extranjeros, becas de estudio en el exterior, intercambio de materiales académicos, y a las posibilidades que ofrecían los organismos de cooperación internacional. La participación de las universidades en actividades internacionales no necesariamente se encontraba vinculada con las prioridades de carácter institucional, ni demandaba un papel activo por parte de estas, sino que se basó en ofertas de cooperación e intereses de los países de los organismos cooperantes e iniciativas espontáneas de profesores o estudiantes que realizaron movilidades al exterior para ampliar sus conocimientos.

En la década de los ochenta, especialmente en Latinoamérica se da una fuerte disminución de oportunidades de cooperación internacional, a raíz de la crisis fiscal de las universidades públicas. Esto sin duda tuvo efectos poco positivos en la educación superior, ya que los recursos disminuyeron y los costos de estudio en el exterior se incrementaron.

En las décadas recientes, como efecto de la globalización del conocimiento, la constante es encontrar cómo las universidades se han visto obligadas a incorporar temas emergentes a su agenda institucional, lo cual ha significado reestructurar su misión y visión, hacer reingenierías sobre la marcha y reenfocar sus planes estratégicos de desarrollo institucional a corto, mediano y largo plazo.

Aquellas instituciones que tienen como meta alcanzar un alto perfeccionamiento en la educación superior, se esfuerzan en tener ventajas significativas en los sistemas de calidad de la enseñanza, desarrollando programas académicos periódicamente monitoreados con indicadores robustos y métodos de evaluación, con el fin de asegurar una sólida formación académica y científica, principalmente en el campo de la formación doctoral. 
En el contexto regional centroamericano y caribeño, la internacionalización y la cooperación académica se han caracterizado por haber desarrollado avances fragmentados, de carácter marginal, los cuales se han ido integrando gradualmente y de manera más organizada, mediante la participación en alianzas estratégicas, convenios o acuerdos de colaboración, programas de estudio, proyectos conjuntos en investigación, incorporación a redes y asociaciones interuniversitarias.

\section{Objetivo general}

- Examinar eidentificar las áreas de mejora en el proceso de gestión de la internacionalización y cooperación académica internacional en la UCR y las instituciones de educación superior en Centroamérica y Caribe en el período 2003-2011, con el fin de fortalecer la integración regional.

\section{Objetivos especificos}

- Documentar las principales acciones de internacionalización y cooperación académica internacional desarrolladas entre la UCR y las IES de Centroamérica y Caribe, en el período 2003-2011.

- Conocer la dinámica de la internacionalización y cooperación académica internacional, en doble vía, para descubrir el nivel de vinculación existente.

- Identificar los logros, las limitaciones relevantes y las buenas prácticas encontradas en el proceso.

- Proponer estrategias que permitan dinamizar y realimentar el quehacer de la internacionalización y la cooperación académica internacional y contribuir efectivamente con la creación de vínculos y lazos para mejorar la integración en la región.

\section{Referente teórico}

\section{Internacionalización y cooperación académica internacional: tendencias mundiales}

Las universidades como instituciones encargadas de impartir la educación superior, han estado desde sus inicios enfocadas en la búsqueda de la verdad científica y la difusión universal del conocimiento, características estas que son inherentes a una dimensión internacional.

La construcción del Espacio Europeo de Educación Superior (EEES) como proceso de convergencia vasto y consolidado fue el resultado de la suscripción de la Declaración de Bolonia por parte de los ministros de educación de 29 países europeos (Declaración de Bolonia, 1999) y que se inició con la Declaración de La Sorbona (1998). Las directrices en el marco del EEES piden que 
los estados miembros de la Unión Europea desarrollen e implementen en sus países los siguientes cinco pilares fundamentales: (i) Estructura de titulaciones común; (ii) Titulaciones conjuntas; (iii) Sistema de Crédito Europeo (ECTS); (iv) Suplemento al Diploma y (v) Garantía de Calidad.

La última Conferencia Mundial sobre la Educación Superior (CMES) desarrollada con el lema "La nueva dinámica de la Educación Superior y la búsqueda del cambio social y el desarrollo", celebrada en la sede de la Organización de las Naciones Unidas para la Educación, la Ciencia y la Cultura (UNESCO, 2009) en París, Francia; mantuvo la esencia en los resultados alcanzados en la primera declaración (CMES-UNESCO, 1998), y, las recomendaciones de las seis Conferencias Regionales (Cartagena de Indias, Macao, Dakar, Nueva Delhi, Bucarest y El Cairo) de Educación Superior (CRES) que le precedieron.

En los artículos del 24 al 34 de la Declaración CMES (UNESCO, 2009), se hace referencia a la internacionalización, regionalización y globalización de la educación superior, y en el primer articulado se indica lo siguiente:

Las instituciones de educación superior a nivel mundial tienen la responsabilidad social de ayudar en el rompimiento de la brecha existente en términos de desarrollo entre los distintos países, mediante el aumento de la transferencia de conocimientos más allá de las fronteras, especialmente hacia los países en vía de desarrollo. (p. 4)

Este articulado hace énfasis en que las instituciones de educación superior deben propiciar la internacionalización y las acciones de cooperación internacional basándose en la solidaridad y el respeto mutuo, con el fin de contribuir a reducir la brecha en materia de desarrollo, incrementando la transferencia de conocimientos a través de las fronteras, en particular hacia los países en desarrollo.

\section{Internacionalización y cooperación académica internacional: tendencias para América Latina y Caribe}

El Instituto Internacional de la UNESCO para la Educación Superior en América Latina y el Caribe (IESALC-UNESCO) en colaboración con varios Ministerios de Educación Latinoamericanos, desarrollaron la Conferencia Regional CRES, del 4 al 6 de junio de 2008, en la ciudad de Cartagena de Indias, Colombia. La declaratoria realizada brindó las bases para una estrategia latinoamericana en materia de educación cimentada en el carácter integrador, la cual en los ítems $\mathrm{F}, \mathrm{G}$ y H impulsa la conformación de redes y estudiar mecanismos que minimicen la perdida de profesores e investigadores (fuga de cerebros) altamente calificados vía la movilidad y la integración regional. En lo relacionado con la integración regional e internacionalización, se decretó que:

Es fundamental la construcción de un Espacio de Encuentro Latinoamericano y Caribeño de Educación Superior (ENLACES), el cual debe formar parte de la agenda de los 
gobiernos y los organismos multilaterales de carácter regional. Ello es básico para alcanzar niveles superiores que apunten a aspectos fundamentales de la integración regional: la profundización de su dimensión cultural; el desarrollo de fortalezas académicas que consoliden las perspectivas regionales ante los más acuciantes problemas mundiales; el aprovechamiento de los recursos humanos para crear sinergias en escala regional; la superación de brechas en la disponibilidad de conocimientos y capacidades profesionales y técnicas; la consideración del saber desde el prisma del bienestar colectivo; y la creación de competencias para la conexión orgánica entre el conocimiento académico, el mundo de la producción, el trabajo y la vida social, con actitud humanista y responsabilidad intelectual. (IESALC-UNESCO, 2008, p. 7)

Además, en esta misma conferencia CRES (IESALC-UNESCO, 2008), se resaltó la necesidad de una educación que contribuya eficazmente a:

...la convivencia democrática, a la tolerancia y a crear un espíritu de solidaridad y de cooperación, que construya la identidad continental, que cree las oportunidades para quienes hoy no las tienen y que contribuya, con la creación del conocimiento, a la trasformación social y productiva de nuestras sociedades. (p. 3)

\section{Internacionalización y cooperación académica internacional: Centroamérica y Caribe}

En Centroamérica hace ya más de 60 años que se inició el proceso de integración subregional, evaluación yacreditación, homologación de programas, reconocimientodetítulosygradosacadémicos, desarrollo de carreras a nivel de pre o posgrados y el funcionamiento de redes interuniversitarias. Este proceso coincide con la creación de la Confederación de Universidades de Centroamérica y del Consejo Superior Universitario Centroamericano (CSUCA) (Cordón y Cordón, 2012).

Deacuerdo con Fernández (2012), el CSUCA funciona en el marco del Sistema de Integración Centroamericano (SICA) y está integrado por 16 universidades públicas de Centroamérica y Panamá. Bajo su resguardo funciona el Sistema Centroamericano de Evaluación y Acreditación de la Educación Superior (SICEVAES), con el Consejo Regional de Vida Estudiantil (CONREVE) y con una Red de Sistemas de Información Documental de Universidades Centroamericanas (Red SIID), la cual garantiza la interconexión telemática de los sistemas de información documental de las universidades miembros.

En el área de la gestión de la internacionalización en las universidades centroamericanas se han venido realizando progresos desde mediados del año setenta con la creación de la Oficina de Asuntos Internacionales de la UCR y a mediados de los ochenta con la creación de Oficinas de Relaciones Internacionales (ORI) en varias de las universidades de mayor tradición, tales como: la Universidad de El Salvador, la Universidad de San Carlos de Guatemala, y la Universidad Nacional Autónoma de Nicaragua, en León. 
Corresponde destacar el impulso dado por programas de cooperación europea tales como ALFA durante los años noventa, y mediante el Proyecto INCA, y Erasmus Mundus, con el proyecto CRECES a principios de la segunda década del 2000, en el fortalecimiento de las estructuras organizacionales de estas ORls y favoreciendo los procesos de comunicación con sus pares en la región.

Algunas de estas oficinas, se han constituido en Vicerrectorías que fomentan la Internacionalización, tales como el caso de la Universidad Nacional Autónoma de Honduras -UNAH (2004), según lo indicado en el Artículo 22 de su Ley Orgánica. Asimismo, la Universidad Nacional Autónoma de Nicaragua (1996), en León, mediante el Artículo 27 de los Estatutos del 22 de abril de 1992, crea la Vicerrectoría de Relaciones Externas; por otro lado, la Universidad Católica Redemptoris Mater en Managua, Nicaragua, pese a que cuenta con funcionarios asignados en condición de Vicerrector de Cooperación Externa y Relaciones Internacionales y, Director de esta joven oficina, creada en 2011, continúa denominándose ORI a esta dependencia administrativa.

En el Caribe, los esfuerzos para facilitar los contactos académicos, realización de proyectos colaborativos multilaterales, movilidad estudiantil, impulso de la cooperación e integración y mantenimiento activo de compromisos con la región del Caribe (inglés, francés y holandés), América Latina y otras instituciones de educación superior en el resto del mundo se dan; por un lado, con la intervención de la University of the West Indies $(U W I)^{3}$ y por el otro lado, Días (2008) y Zarur (2008) indican que se realizan mediante los logros alcanzados por la Asociación de Universidades e Institutos de Investigación del Caribe (UNICA)', la cual cumple un importante papel como red dinamizadora que favorece la regionalización de la educación superior en el Caribe, sin desconocer las fuerzas que residen en la historia cultural local y el apoyo a vínculos con América Latina, principalmente a través de universidades puertorriqueñas.

\section{Internacionalización y cooperación académica internacional: Costa Rica}

En Costa Rica, el Ministerio de Planificación Nacional y Política Económica (MIDEPLAN, 2010), en un análisis retrospectivo en el tiempo, expresa que la cooperación internacional se

3 La UWI es una institución autónoma regional y sirve de apoyo a 16 países y territorios en el Caribe que tienen el inglés como lengua materna: Anguila, Antigua y Barbuda, Las Bahamas, Barbados, Belice, las Islas Vírgenes Británicas, la de las Islas Caimán, Dominica, Granada, Jamaica, Montserrat, San Cristóbal y Nieves, Santa Lucía, San Vicente y las Granadinas, Trinidad y Tobago, y las Islas Turcas y Caicos. Estos países son miembros de la Comunidad de Naciones del Caribe (CARICOM).

4 La UNICA tiene como asociados a: University of the Virgin Islands, Universidad de Puerto Rico, Universite d'Etat d'Haiti, Universite des Antilles et de La Guyane, Universite Quisqueya (Haití), Universidad Tecnológica del Caribe (RD), Universidad Nacional Pedro Henríquez Urena, Universidad Simón Bolívar (Venezuela), Instituto Tecnológico de Santo Domingo, Universidad Interamericana de Puerto Rico, Universidad Iberoamericana (RD), University of the Netherland Antilles, Universidad del Sagrado Corazón (Puerto Rico), University Of West Florida \& Sbdc Network, University of the West Indies, Pontifica Universidad Católica Madre y Maestra (RD), Universidad Tecnológica de Santiago (RD), University Of Technology (Jamaica), Universite Notre Dame D'Haiti, University Of Guyana, Universite Caraibe (Haiti), Institute of International Relations (Trinidad), Institute Of Social \& Economic Research, U.W.I., Institute Of Caribbean Studies, U.P.R., Instituto de Estudios Caribeños (Colombia) y el Observatorio del Caribe Colombiano. 
inició en la década de los noventa, manteniéndose relativamente constante a partir de 1994 como objeto de desarrollo y resalta el beneficio de la cooperación técnica y financiera no reembolsable en el ámbito de la educación y capacitación mediante la generación de recursos que favorecen la movilidad de expertos o profesionales, docentes e investigadores universitarios, en asesorías y consultorías de carácter científico o tecnológico en el marco de programas y/o proyectos a cargo del organismo estatal.

A finales del siglo XX e inicios del XXI la educación superior costarricense no estuvo exenta de la serie de transformaciones que venían generándose en los países desarrollados. En Costa Rica se advierten avances encaminados a consolidar la cooperación interinstitucional, regional (al interior del país) e internacional bajo el principio de la integralidad, buscando optimizar la calidad, la investigación y la innovación, actividades estas que son consideradas dimensiones claves en el quehacer académico.

El proceso de internacionalización de la educación superior en Costa Rica toma mayor fuerza con el trabajo desarrollado por el Consejo Nacional de Rectores y la Oficina de Planificación de la Educación Superior (CONARE-OPES, 2005) al concebir el Plan Nacional de la Educación Superior Universitaria Estatal - PLANES (2006-2010), el cual se refiere a la capacidad de las instituciones para responder tanto a las demandas y necesidades del país como a las del nuevo orden mundial, con diversas perspectivas, instrumentos y modalidades. Este PLANES correspondería a la séptima versión que cubre un quinquenio de labores.

CONARE-OPES (2010), en la actualidad, mantiene en ejecución la octava versión del documento PLANES (2011-2015), el cual tiene como objetivo general contribuir con el desarrollo integral de programas y proyectos inter y transdisciplinarios, intersedes, interuniversitarios e interinstitucionales, de manera tal que se beneficien los diversos grupos de interés y usuarios de los servicios universitarios costarricenses, para implementar el plan las diversas acciones se encuentran agrupadas en los siguientes cinco ejes: Pertinencia e impacto, Acceso y equidad, Aprendizaje, Ciencia y tecnología, y Gestión. Este mismo documento ubica la regionalización e internacionalización de la educación superior en Costa Rica en el Eje 1 Pertinencia e Impacto:

...correspondealavinculacióndelasuniversidadesconelentorno,entodassusdimensiones: social, económica, ambiental e incluso política. En ese contexto, las instituciones buscarán que sus áreas sustantivas tengan un papel preponderante, innovador y de vanguardia en la propuesta de programas académicos, proyectos de investigación y acciones de desarrollo social en temas estratégicos como articulación del sistema educativo, desarrollo regional, ambiente e internacionalización del quehacer universitario. (CONARE-OPES, 2010, p. 91)

De acuerdo con lo anterior, las universidades costarricenses han tenido que trabajar arduamente en cada una de sus áreas sustantivas incluida la acción social, donde están reflejadas acciones que articulan el sistema educativo en el ámbito local, nacional, regional e internacional. 
En el caso de Costa Rica, el área de internacionalización y cooperación académica internacional en cada una de las cinco universidades estatales posee su respectiva oficina ${ }^{5}$ de relaciones internacionales: Universidad de Costa Rica (Oficina de Asuntos Internacionales y Cooperación Externa), Universidad Nacional (Oficina de Cooperación Técnica Internacional), Instituto Tecnológico de Costa Rica (Dirección de Cooperación), Universidad Estatal a Distancia (Dirección de Internacionalización y Cooperación) y Universidad Técnica Nacional (Dirección de Cooperación Externa). De igual manera, algunas de las 52 universidades privadas que se encuentran funcionando en Costa Rica cuentan con sus oficinas de relaciones internacionales con diferente grado de desarrollo.

\section{Internacionalización y cooperación académica internacional: Universidad de Costa Rica}

La Universidad de Costa Rica con 75 años de experiencia y con liderazgo regional en educación superior, asume, una vez más, el reto de otorgarle a la academia el sentido más amplio y ambicioso, lo cual implica pensar y actuar siempre en comunidad, con el objetivo de proyectarse hacia una esfera social más amplia (Jensen-Pennington, 2015).

La internacionalización de la UCR, es igualmente, un ejemplo de cómo este proceso parte desde los orígenes institucionales con una visión de largo plazo, con profundo compromiso institucional y se nutre del apoyo internacional, pero sobre todo de un significativo aporte de la Institución. El éxito del proceso se fundamenta en su capacidad para evolucionar y adaptarse a los diversos cambios que le plantea el escenario local, regional e internacional a la educación superior costarricense y, en particular, el panorama que enfrenta la UCR.

La estrategia internacional que emprende durante sus inicios la UCR tiene gran importancia para el desarrollo de los nuevos programas de estudio, mejora de los métodos de enseñanza, y crecimiento de la infraestructura necesaria, con el fin de responder a los objetivos que se trazaron para la Institución. La evolución del proceso de internacionalización institucional, también resalta los acuerdos del III Congreso Universitario en Asamblea Universitaria como punto de inflexión clave para hacer desarrollar esta temática al interior de la universidad (UCR, 1972).

Cabe señalar que en el Plan Estratégico Institucional (PEI) ejecutado en el periodo 20082012 en los ejes estratégicos: Docencia, Investigación científica y tecnológica, Acción Social, Desarrollo Académico, Vida Estudiantil y Gestión Institucional se hizo referencia al compromiso de la UCR con la internacionalización y la cooperación académica internacional.

5 Para mayor información de estas oficinas, se puede ingresar a las siguientes direcciones electrónicas: Universidad de Costa Rica: www.oaice.ucr.ac.cr Universidad Nacional: http://www.octi.una.ac.cr/ Instituto Tecnológico de Costa Rica: http://www.tec.ac.cr/sitios/Vicerrectoria/vie/cooperacion/Paginas/default.aspx Universidad Estatal a Distancia: http://dinamico.uned.ac.cr/viplan/index.php/dic

Universidad Técnica Nacional: http://utn.ac.cr/index.php?option=com_content\&view=article\&id=180\&ltemid=123 
En la actualidad, está en curso el PEl-2013-2017 el cual a diferencia del PEI-2008-2012 otorga un peso mayor al proceso de Internacionalización constituyéndolo en un eje separado y bien estructurado (UCR-PEI, 2013).

La Tabla 1, muestra el objetivo estratégico definido, las estrategias a seguir y señala los vínculos con las Políticas Institucionales (2010-2014) con el propósito de facilitar a la comunidad universitaria, la visualización de la relación de estos documentos y mediante el compromiso y esfuerzo conjunto de contribuir a su cumplimiento (Calderón-Morales, 2013).

\section{Tabla 1}

Plan Estratégico Institucional 2013-2017 particularidades correspondientes al Eje 4 de Internacionalización en la UCR

\begin{tabular}{|c|c|c|}
\hline OBJETIVO ESTRATÉGICO & ESTRATEGIA & $\begin{array}{c}\text { VINCULACIÓN } \\
\text { POLÍTICAS INSTITUCIONALES } \\
(2010-2014)\end{array}$ \\
\hline \multirow{4}{*}{$\begin{array}{l}\text { Establecer redes de cooperación e } \\
\text { Intercambio que consoliden la posición de } \\
\text { la UCR en el escenario académico } \\
\text { internacional y fomenten la movilidad } \\
\text { activa de docentes, estudiantes y personal } \\
\text { administrativo, enriqueciendo nuestro } \\
\text { acervo cientifico y cultural, a partir del } \\
\text { contacto con la diversidad de } \\
\text { experiencias. }\end{array}$} & \multirow[t]{2}{*}{$\begin{array}{l}\text { 1. Fomentar el desarrollo de redes } \\
\text { académicas -formales y no formales-, en los } \\
\text { ámbitos nacional e internacional. }\end{array}$} & $\begin{array}{l}\text { 1.3.1. Promoverá las relaciones } \\
\text { internacionales y de cooperación para } \\
\text { fortalecer sus actividades sustantivas por } \\
\text { medio de la participación en iniciativas } \\
\text { internacionales de carácter interinstitucional } \\
\text { y la firma de acuerdos y convenios. }\end{array}$ \\
\hline & & $\begin{array}{l}\text { 2.2.8. Fomentará el trabajo en redes que } \\
\text { propicien una mayor integración de las } \\
\text { políticas institucionales y del quehacer } \\
\text { universitario. }\end{array}$ \\
\hline & \multirow[t]{2}{*}{$\begin{array}{l}\text { 2. Fomentar la movilidad de docentes, } \\
\text { estudiantes y personal administrativo tanto } \\
\text { nacional como Internacionalmente. }\end{array}$} & $\begin{array}{l}\text { 1.3.3. Promoverá y facilitará la movilidad } \\
\text { internacional del personal docente, } \\
\text { administrativo y de la población estudiantil, } \\
\text { como un medio para fortalecer la educación } \\
\text { superior pública. }\end{array}$ \\
\hline & & $\begin{array}{l}\text { 2.1.2. Fortalecerá los mecanismos para la } \\
\text { formación y la capacitación que contribuyan } \\
\text { al más amplio desarrollo de su personal } \\
\text { académico y administrativo. }\end{array}$ \\
\hline
\end{tabular}

Nota: Esquema elaborado por las autoras para la investigación con base en Calderón-Morales (2013, p. 21).

En las Políticas Institucionales (2010-2014) aprobadas por el Consejo Universitario en sesión extraordinaria 5296, artículo único, del 13-10-2008, publicadas en La Gaceta Universitaria 40-2008 del 21-11-2008 y, su vinculación a la estrategia y objetivos expuestos en la Tabla 1 se refiere a que la estrategia 1 coincide con las políticas expresadas en los ítems 1.3.1 y 2.2.8; mientras que, la estrategia 2 se complementa con los ítems 1.3.3 y 2.1.2 en vínculos directos con la Internacionalización.

\section{Procedimiento metodológico}

El estudio presenta en forma organizada la información básica de las acciones realizadas, con el fin de caracterizar la situación actual de la Institución frente al proceso de internacionalización 
y cooperación académica internacional con las IES de Centroamérica y Caribe en el período 20032011. La información que aquí se genera, en el entendido de ser un diagnóstico, permite visualizar en forma esencial los procesos exitosos, las oportunidades, así como también los riesgos y/o dificultades que deberá superar la UCR en el futuro inmediato, a mediano o a largo plazo.

La investigación es de carácter descriptiva y se sustenta utilizando técnicas cualitativas para la presentación y análisis de datos. Emplea diversas fuentes para la compilación de información, así como la técnica de entrevista abierta (ver Anexo 1), con la finalidad de recabar información para caracterizar la cooperación e intercambio internacional desarrollado por la UCR con las IES de la región.

La información recopilada es posteriormente sistematizada, organizada y se realiza un referente explicativo sobre las inquietudes y la problemática que se planteó en el objeto de esta investigación.

\section{Sistematización, análisis y discusión de resultados}

\section{Acción 1. Convenios de cooperación}

La OAICE de la UCR realiza la gestión y seguimiento a los convenios internacionales que se establecen con las diferentes IES u otros organismos que apoyan las actividades desarrolladas por la universidad en el cumplimiento de su misión.

Número de convenios

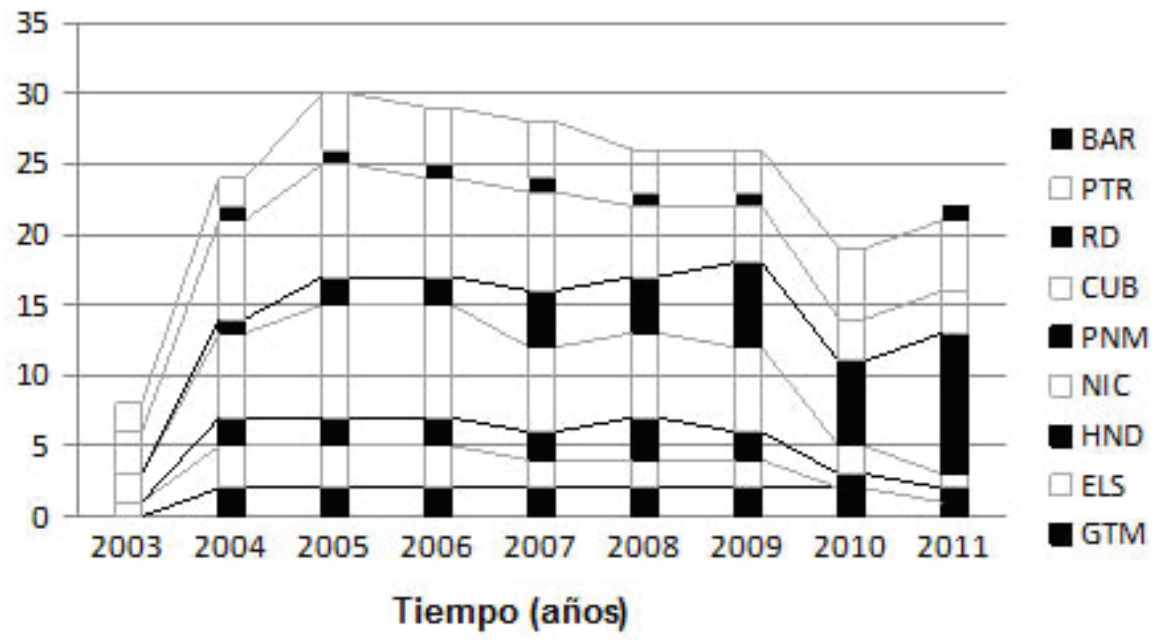

Nota: Elaboración propia de las autoras a partir de datos obtenidos de la OAICE de la UCR, 2013.

Figura 1. Convenios de cooperación vigentes de la UCR con IES de países de Centroamérica y algunos del Caribe. GTM= Guatemala; ELS= El Salvador; $\mathrm{HND}=$ Honduras; $\mathrm{NIC}=$ Nicaragua; $\mathrm{PNM}=$ Panamá; $\mathrm{CUB}=\mathrm{Cuba}$; $\mathrm{RD}=$ República Dominicana; PTR= Puerto Rico y BAR= Barbados 
Para el período 2003-2011 la UCR mantuvo vigentes un promedio anual de 23,5 convenios de cooperación técnica, académica, científica o cultural con universidades de Guatemala, El Salvador, Honduras, Nicaragua, Panamá, Cuba, República Dominicana, Puerto Rico y Barbados (Figura 1).

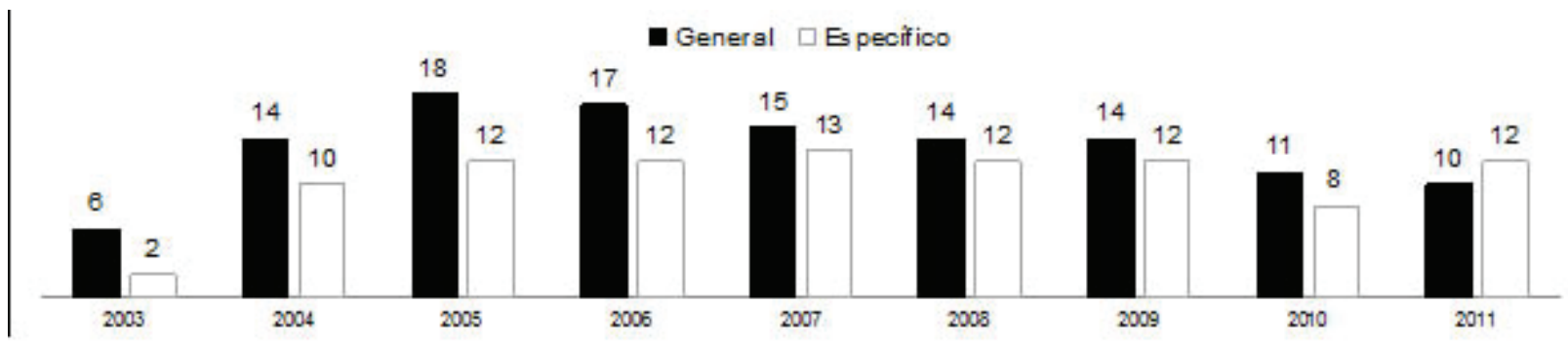

Nota: Elaboración propia de las autoras a partir de datos obtenidos de la OAICE de la UCR, 2013.

Figura 2. Tipos de convenios de cooperación por la naturaleza del carácter general o específicos, para el periodo del 2003-2011 con IES de países de Centroamérica y algunos del Caribe. GTM= Guatemala; ELS=El Salvador; HND= Honduras; $\mathrm{NIC}=$ Nicaragua; $\mathrm{PNM}=$ Panamá; $\mathrm{CUB}=\mathrm{Cuba}$, $\mathrm{RD}=$ República Dominicana; $\mathrm{PTR}=$ Puerto Rico y $\mathrm{BAR}=$ Barbados

En la Figura 2, el estudio realizado se sistematiza en función del tipo de convenio de cooperación técnica, académica, científica o cultural, atendiendo el carácter general o específicos. En lo general se indican expresiones formales de intención para participar en diferentes actividades de cooperación técnica, académica, científica o cultural. Mientras que en los específicos se concretizan los objetivos, así como las obligaciones, responsabilidades, beneficios e implicaciones legales y financieras. Esta figura muestra la evolución cronológica de los tipos de convenios con universidades centroamericanas de Nicaragua, Panamá y Honduras y en el área del Caribe con Puerto Rico, Cuba, República Dominicana y Barbados, se observa que de un total de 212 convenios: 119 son de carácter general y 93 son acuerdos específicos para movilidad estudiantil y académica.

En forma resumida, "de los 313 convenios vigentes con 173 instituciones a nivel mundial, a diciembre de 2011, se podría inferir que de este número, únicamente el $7 \%$ representaría los acuerdos vigentes de la institución con las IES de la región" (UCR, 2012, p. 19). 


\section{Acción 2. Movilidad Académica}

Este estudio hace referencia a lo académico para indicar acciones con docentes e investigadores. Los docentes de la UCR fueron privilegiados en esta última década por políticas institucionales dirigidas a fortalecer la internacionalización y, a su vez, formar cuadros profesorales de alto nivel académico en instituciones de gran prestigio en el mundo.

En el período en estudio se desarrolló una importante movilidad académica de docentes e investigadores de universidades centroamericanas y caribeñas a la UCR, mediante las siguientes modalidades auspiciadas por la UCR y algunas cofinanciadas por Agencias de Cooperación Internacional, lo cual genero la siguiente clasificación: (a) Programa de Académicos Visitantes; (b) Programa de Cooperación Francesa; (c) Programa de apoyo al intercambio académico regional de docentes del Servicio Alemán de Intercambio Académico -DAAD; (d) Programa de Beneficios del Consejo Universitario de UCR mediante Reglamento y (e) Programa de Becas Cortas y de Becas de Posgrado en el Exterior.

\section{a. Programa de Académicos Visitantes (PAV)}

Este Programa es una modalidad creada por la UCR en 1998, con el fin de propiciar la movilidad académica-administrativa y facilitar la participación de académicos destacados provenientes de universidades extranjeras, durante periodos de dos semanas máximo, en apoyo a los programas académicos, de investigación, de acción social y gestión universitaria (Figura 3).

EI PAV durante el período en análisis logró apoyar la visita de 221 académicos procedentes de la región, en mayor número provenientes de Nicaragua (40), El Salvador (35), Guatemala (33) y Panamá (29) por Centroamérica, así como por la región caribeña principalmente por Cuba (38) y Puerto Rico (20). 


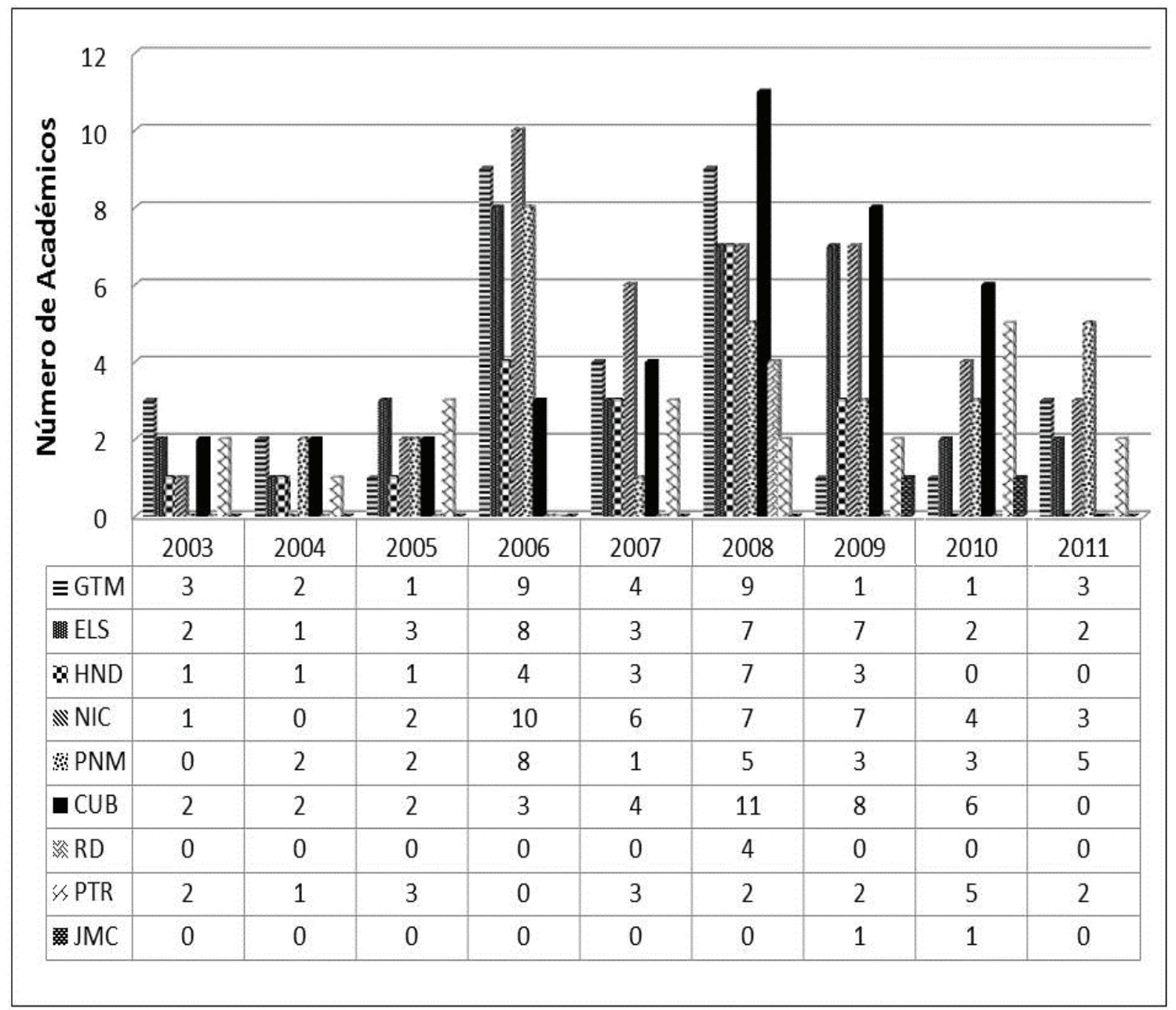

Nota: Elaboración propia de las autoras a partir de datos obtenidos de la OAICE de la UCR, 2013.

Figura 3. Programa de Académicos Visitantes (PAV) provenientes de países de Centroamérica y del Caribe, período 2003- 2011. GTM= Guatemala; $E L S=E l$ Salvador; $H N D=$ Honduras; $N I C=$ Nicaragua; $P N M=$ Panamá; $C U B=$ Cuba; RD= Republica Dominicana; PTR= Puerto Rico y JMC= Jamaica 

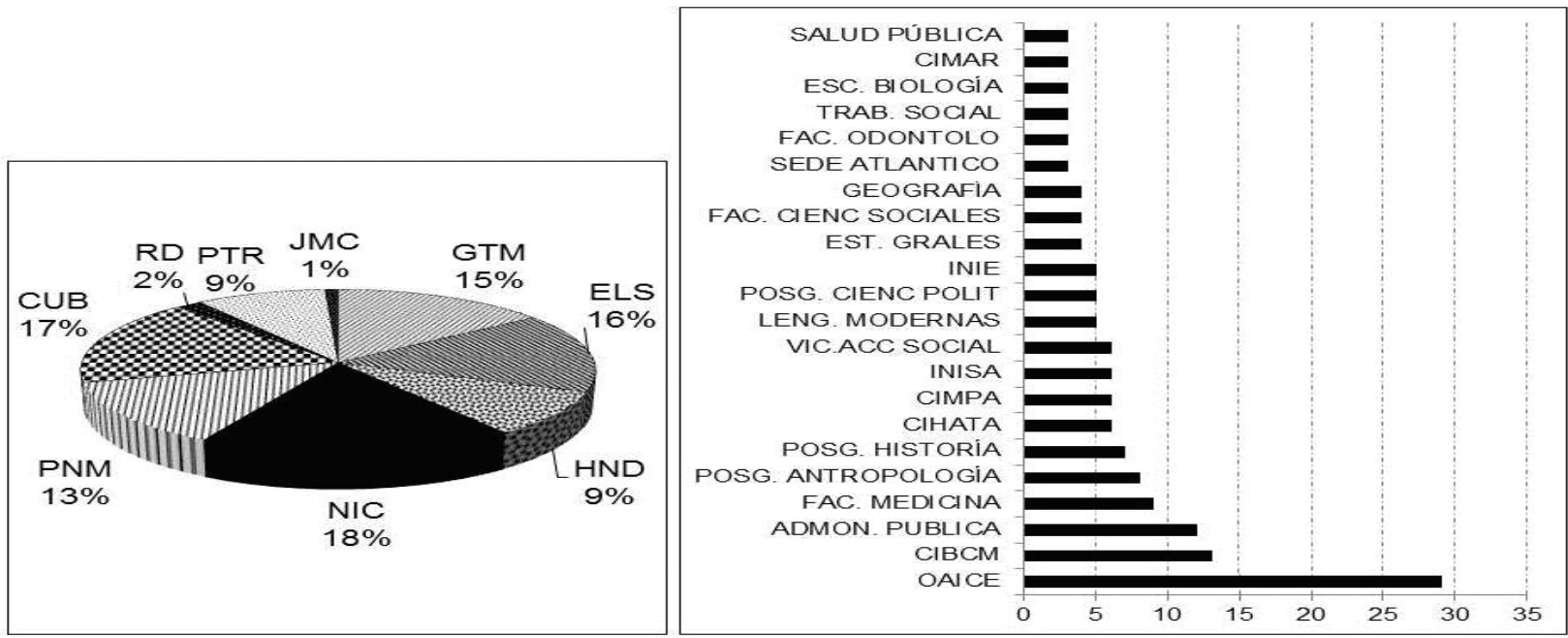

Nota: Elaboración propia de las autoras a partir de datos obtenidos de la OAICE de la UCR, 2013.

Figura 4. Porcentaje de académicos del programa PAV provenientes de países de Centroamérica y del Caribe y unidades académicas en UCR receptoras en el periodo 2003-2011. A la izquierda porcentaje de visitantes por país de procedencia y a la derecha unidades académicas UCR receptoras de académicos, muestra seleccionada de las más frecuentes. GTM= Guatemala; $E L S=E l$ Salvador; $H N D=$ Honduras; $\mathrm{NIC}=$ Nicaragua; $\mathrm{PNM}=$ Panamá; $\mathrm{CUB}=$ Cuba; $\mathrm{RD}=$ Republica Dominicana; $\mathrm{PTR}=$ Puerto Rico y JMC= Jamaica. CIMAR= Centro de Investigación en Ciencias del Mar y Limnología; INIE= Instituto de Investigación en Educación; INISA= Instituto de Investigaciones en Salud; $\mathrm{CIMPA}=$ Centro de Investigación en Matemáticas Puras y Aplicadas; CIHATA= Centro de Investigación en Hematología y Trastornos Afines; $\mathrm{ClBCM}=$ Centro de Investigación en Biología Celular y Molecular y OAICE = Oficina de Asuntos Internacionales y Cooperación Externa

La Figura 4 muestra, a la izquierda, los porcentajes de movilidad de los académicos visitantes desde los países de procedencia en el marco del PAV. Se puede evidenciar que de Centroamérica: Nicaragua, El Salvador y Guatemala exhiben los más altos porcentajes, y que para el Caribe el mayor flujo de académicos viene de Cuba, seguido por Puerto Rico y por último en su orden República Dominicana (2\%) y Jamaica (1\%).

En el costado derecho de la Figura 4, se despliega un listado (únicamente 22 unidades) reducido que corresponde a tan solo el $31,4 \%$ de las aproximadamente 70 unidades académicas que sirvieron de anfitrionas a los 221 académicos que visitaron la UCR durante este periodo de estudio en la iniciativa PAV. Como se puede observar, la OAICE es la dependencia de la universidad solicitante del mayor número de académicos de la región; asimismo, le siguió el Centro de Biología Celular y Molecular (CIBCM), la Escuela de Administración Pública, la Facultad de Medicina y los posgrados en Antropología e Historia, entre otras que aparecen indicados en esta misma figura. 


\section{b. Programa de Cooperación Francesa}

En este estudio interesa destacar el impacto académico para la UCR y la región generado en el marco del Convenio existente entre la UCR y el Instituto de Altos Estudios de América Latina (IHEAL) a través de la Universidad de la Sorbona Nueva París III desde el 2001, bajo el auspicio del Centro Cultural y de Cooperación para América Central (CCCAC), denominado hoy día como el Instituto Francés de Cooperación para América Central.

\section{Tabla 2}

Académicos visitantes de países de Centroamérica y del Caribe, 2003-2011. COOP. FRANCESA= Cooperación bilateral con Embajada de Francia. $C C C A C=$ Centro Cultural y de Cooperación para América Central e IHEAL= Instituto de Altos Estudios de América Latina

\begin{tabular}{|c|c|c|}
\hline AÑO & \multicolumn{2}{c}{ PROGRAMAS } \\
COOP. & CCCAC/ \\
FRANCESA & IHEAL \\
\hline 2003 & 0 & 0 \\
\hline 2004 & 7 & 0 \\
\hline 2005 & 0 & 10 \\
\hline 2006 & 0 & 3 \\
\hline 2007 & 0 & 2 \\
\hline 2008 & 9 & 0 \\
\hline 2009 & 0 & 6 \\
\hline 2010 & 0 & 3 \\
\hline 2011 & 0 & 0 \\
\hline TOTAL & 16 & 24 \\
\hline
\end{tabular}

Nota: Elaboración propia de las autoras a partir de datos obtenidos de la OAICE de la UCR, 2013.

A partir de esta alianza estratégica se han desarrollado desde 2005 una serie de módulos de formación en la UCR que han fortalecido actividades académicas en la región centroamericana, por medio de la participación de académicos visitantes, para un total de 24 en el período 2005-2011 (Tabla 2). En ese período además UCR cofinanció la visita de 16 académicos centroamericanos respaldados en el Convenio de Cooperación entre la UCR y la Embajada de Francia. 


\section{c. Programa de apoyo al intercambio académico regional de docentes del Servicio} Alemán de Intercambio Académico -DAAD

Otra importante actividad de cooperación desarrollada en la UCR, a favor de la movilidad académica hacia y desde la región que interesa resaltar, es el trabajo desarrollado conjuntamente con el auspicio del Servicio Alemán de Intercambio Académico (DAAD).

Este programa favorece la formación de capacidades de docentes de la región en programas de maestría y doctorado de la UCR, el cual ha registrado un total de 104 beneficiarios como se muestra (Figura 5) en el período 2003-2009 y en la entrevista a la M. Sc Zamora (Anexo 1).
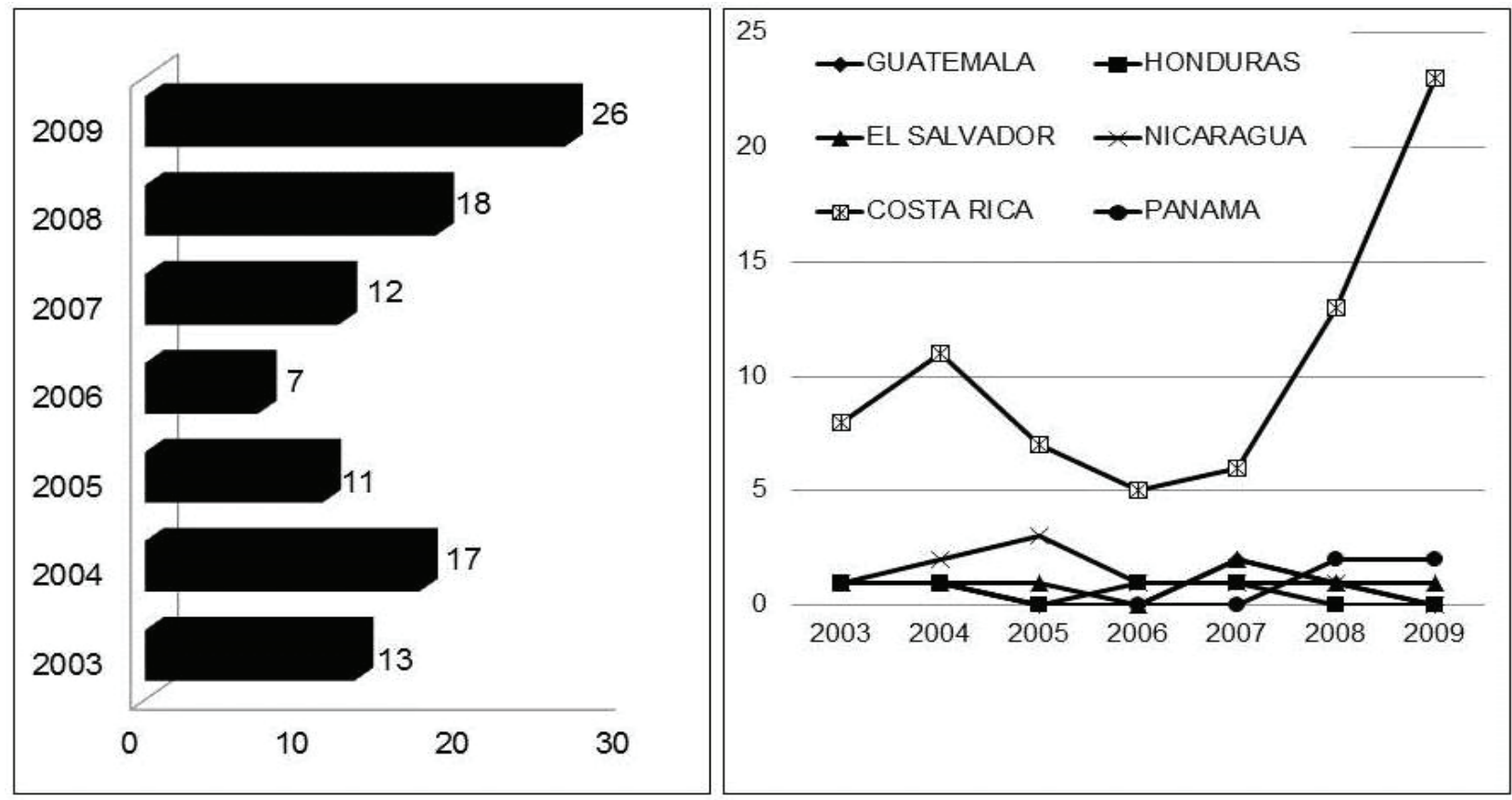

Nota: Elaboración propia de las autoras a partir de datos obtenidos en entrevista a Coordinadora del Organismo Alemán DAAD, 2010.

Figura 5. Número de becas para formación de docentes de la región a nivel de posgrado auspiciado por el Servicio Alemán de Intercambio Académico -DAAD en el periodo 2003-2009. A la derecha se ilustra el desglose de becas otorgadas por países favorecidos. Datos años 2010 y 2011 a la fecha del cierre de este documento no fue posible obtenerlos 
A partir de esta información y la que se encuentra consignada en la parte derecha de la Figura 5, se puede deducir que mediante la cofinanciación del DAAD-UCR para este periodo se concedió un mayor número de becas a las IES de Costa Rica en un 70,2\% seguidas en su orden por aquellas de Nicaragua (8,6\%); El Salvador (6,7\%); Panamá $(5,8 \%)$; Guatemala (4,8\%) y Honduras (3,8\%).

\section{d. Programa de Beneficios del Consejo Universitario de UCR mediante Reglamento}

Desde el año de 1996 y con algunas reformas (incluida la más reciente en UCR-La Gaceta Universitaria 7-2010, 08-06-2010), la UCR reglamentó la asignación de apoyo financiero para funcionarios o funcionarias universitarios (docentes, investigadores y/o administrativos), incluidos viáticos, derechos de inscripción y otros relacionados con participación en eventos en el exterior. Las actividades a las que se hacen referencia pueden tratarse de: (i) eventos de corta duración, máximo una semana, de carácter académico o administrativo, relacionados con el quehacer universitario; o (ii) cursos cortos de actualización o capacitación, cuya duración no exceda de un máximo de siete días.

\section{Tabla 3}

Funcionario/as de la UCR movilizado/as hacia diferentes partes de la región y el Caribe, periodo 2003-2011. $B E L=$ Belice; $G T M=$ Guatemala; $E L S=E I$ Salvador; $H N D=$ Honduras; $N I C=$ Nicaragua; $P N M=$ Panamá; $C U B=C u b a ; R D=$ República Dominicana; PTR= Puerto Rico; TTB= Trinidad y Tobago; BRB= Barbados; JMC= Jamaica; HAT= Haití; DOM= Dominica; MRT= Martinica y GRN= Grenada

\begin{tabular}{|c|c|c|c|c|c|c|c|}
\hline Pais & $\begin{array}{l}\text { Funcionario/as } \\
\text { Movilizado/as }\end{array}$ & País & $\begin{array}{l}\text { Funcionario/as } \\
\text { Movilizado/as }\end{array}$ & País & $\begin{array}{l}\text { Funcionario/as } \\
\text { Movilizado/as }\end{array}$ & Pais & $\begin{array}{l}\text { Funcionario/as } \\
\text { Movilizado/as }\end{array}$ \\
\hline BEL & 7 & NIC & 237 & PTR & 39 & HAT & 4 \\
\hline GTM & 268 & PNM & 363 & тТв & 4 & DOM & 1 \\
\hline ELS & 151 & сUв & 256 & BRB & 2 & MRT & 2 \\
\hline HND & 132 & RD & 100 & JMC & 15 & GRN & 1 \\
\hline & & & & & & TOTAL & 1.582 \\
\hline
\end{tabular}

Nota: Elaboración propia de las autoras a partir de datos obtenidos de las publicaciones en La Gaceta Universitaria de la UCR, periodo del 2003 al 2011 (2013).

El estudio exhaustivo de las a probaciones en Actas, publicadas por el Consejo Universitario en La Gaceta Universitaria para el periodo 2003-2011, permitió determinar que en ese periodo se movilizó un total de 5.772 (dato no mostrado) funcionario/as de la UCR a los diferentes 
destinos en el mundo. El porcentaje más alto $(27,4 \%)$ de movilizados se concentró en la región Centroamericana y del Caribe. El segundo destino en importancia estuvo en cifras muy cercanas que no fueron significativamente diferentes y quedó compartido por los países de Norteamérica, México y Suramérica. El cuarto lugar de preferencia fue para los países de Europa. Los destinos minoritarios permanecieron en su orden de frecuencia a los países de Asia, África y Oceanía.

Las cifras contabilizadas por país receptor para el presente estudio (Tabla 3) registran que Panamá recibe el 22,9\% de personal de la UCR seguido por otros países de Centroamérica: Guatemala, Nicaragua, El Salvador y Honduras. En el mismo escenario para el Caribe sobresale Cuba, que recibe un $16,2 \%$ y seguidamente República Dominicana y Puerto Rico y, un poco más distante aparecen las demás islas caribeñas que se mencionan en este estudio.

Este estudio también pudo comprobar que de los 5.772 académicos o administrativos movilizados: 2.566 corresponde a mujeres y 3.206 a hombres, lo cual ratifica que existe prácticamente una paridad de género, mujeres: hombres $(44,5):(55,5)$ respectivamente, en el personal de la UCR que se moviliza.

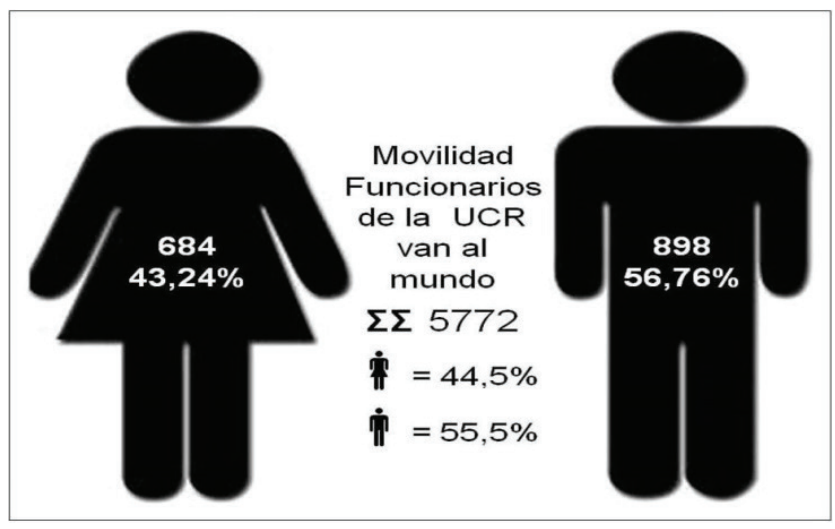

Nota: Elaboración propia de las autoras a partir de datos obtenidos de La Gaceta Universitaria de la UCR, para el periodo 2003-2011 (2013).

Figura 6. Distribución en función del género de funcionario/as de la UCR movilizado/as a diferentes países de Centroamérica y Caribe, periodo 2003-2011

La Figura 6 presenta para la región y el Caribe el porcentaje de funcionarios/as movilizados/ as según género, observándose en el centro de cada figura las cifras de 684 para las mujeres y 898 para los hombres, por lo cual, en términos de porcentajes estaríamos en una relación $(43,2):(56,8)$ respectivamente, siendo los valores comparativamente no muy distantes. Además se visualiza en el centro de este la sumatoria del comportamiento de movilidad de docentes en el mundo apoyados por este mismo Programa. 
La Figura 7 hace una presentación más a fondo de la movilidad de docentes, investigadores y administrativos de la UCR hacia la región.

A partir de los datos generados en este estudio, se advierte que el $60 \%$ de los funcionario/as movilizado/as hacia Centroamérica y Caribe se reparten en 30 dependencias. Entre los diez más frecuentes en su orden se encuentran: Sección de Transportes (168); Escuela Centroamericana de Geología (53); Vicerrectoría de Acción Social (50); Sede Regional de Guanacaste (42); Sede Regional de Occidente (40); Sede Regional del Atlántico (35); Vicerrectoría de Investigación (34); Escuela de Administración Pública (33); Sistema Universitario de televisión - Canal 15 (33) y Vicerrectoría de Docencia (32).

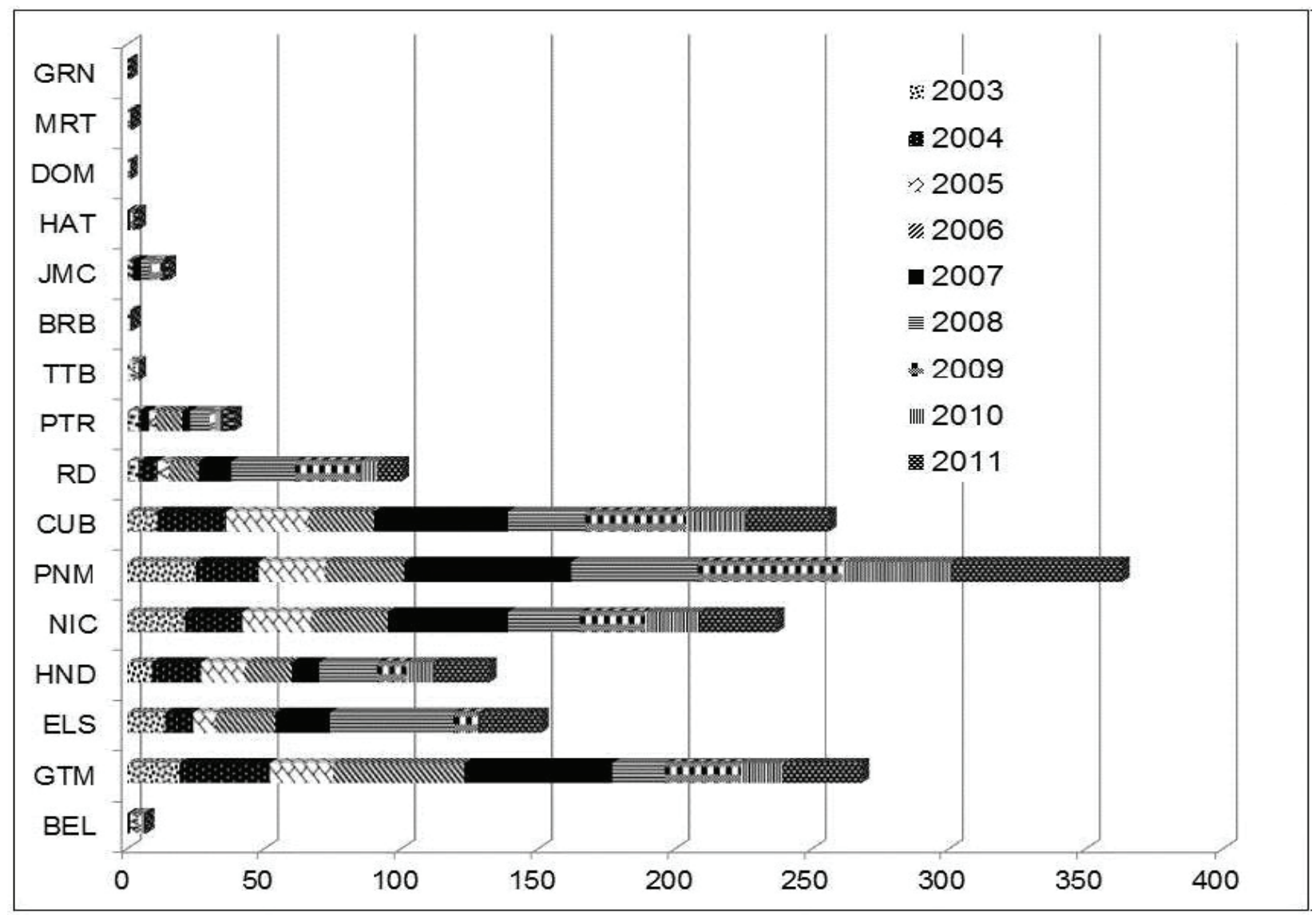

Nota: Elaboración propia de las autoras a partir de datos obtenidos de las publicaciones en La Gaceta Universitaria de la UCR con datos del Consejo Universitario de la UCR, periodo del 2003 al 2011 (2013).

Figura 7. Funcionario/as de la UCR movilizado/as hacia diferentes partes del mundo que han sido beneficiado/ as por reglamentación del Consejo Universitario, periodo 2003 - 2011. BEL= Belice; GTM= Guatemala; ELS= El Salvador; $\mathrm{HND}=$ Honduras; $\mathrm{NIC}=$ Nicaragua; $\mathrm{PNM}=$ Panamá; $\mathrm{CUB}=\mathrm{Cuba} \mathrm{RD}=$ República Dominicana; $\mathrm{PTR}=\mathrm{Puerto}$ Rico; $\mathrm{TTB}=$ Trinidad y Tobago; $\mathrm{BRB}=$ Barbados; $\mathrm{JMC}=$ Jamaica; $\mathrm{HAT}=$ Haití; $\mathrm{DOM}=$ Dominica; $\mathrm{MRT}=$ Martinica y GRN= Grenada 
Si bien la Sección de Transportes realizó un total de 168 viajes hacia los diferentes países de la región, este estudio no pudo precisar el número de estudiantes, profesores, investigadores o administrativos que se movilizaron durante este periodo en esos viajes. Este hubiese sido un dato revelador de la magnitud de acciones que la UCR desarrolla en la región. Sin embargo, se estima que podría ser una cifra que fácilmente puede pasar de mil, si considerásemos un promedio exiguo de seis personas por viaje. La segunda posición en estos resultados del estudio es para la Escuela Centroamericana de Geología al tratarse de un programa de corte centroamericano y que promueve alianzas casi permanentes con la Región.

El otro dato que llamó particularmente la atención fue el dinamismo que tuvo el personal de las Sedes Regionales y sus respectivos Recintos (Figura 8, parte izquierda) en el marco del programa de beneficios financieros reglamentados por la Universidad y ratificados por el Consejo Universitario. Durante el periodo se movilizaron 162 funcionarios siendo este un trabajo sistemático a lo largo del tiempo.
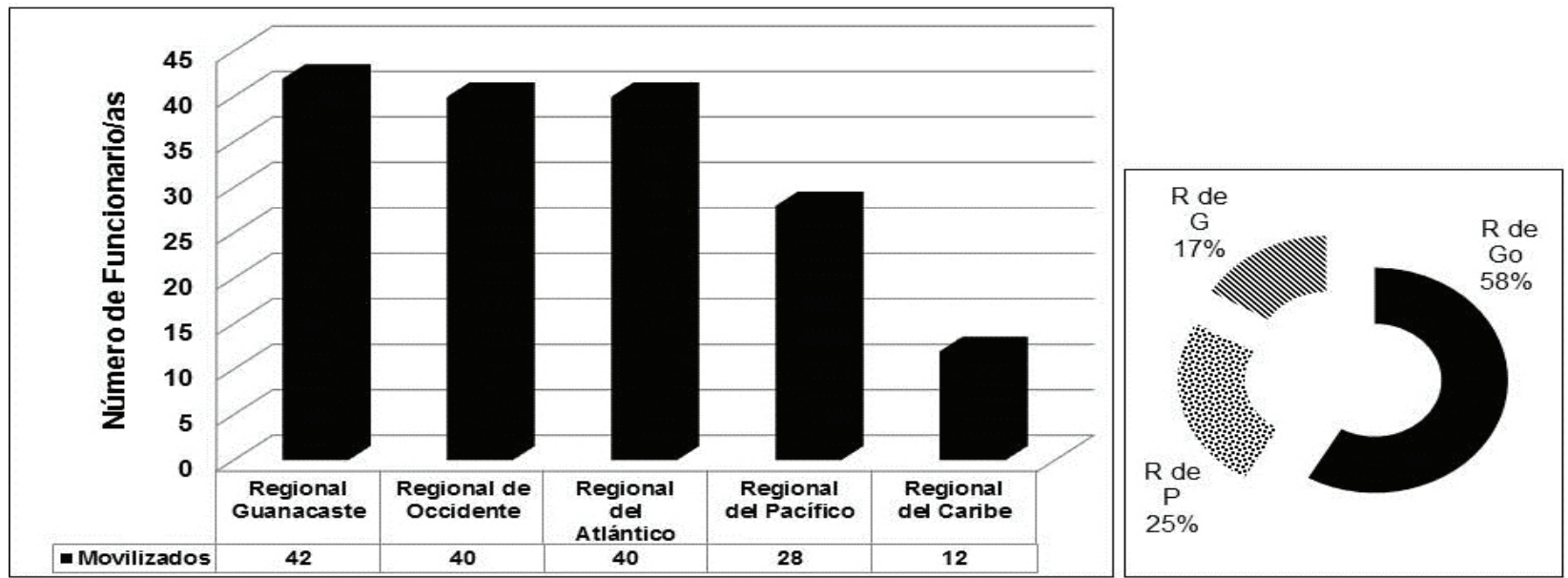

Nota: Elaboración propia de las autoras a partir de datos obtenidos de las publicaciones en La Gaceta Universitaria de la UCR, periodo del 2003 al 2011 (2013).

Figura 8. Movilización académica de funcionario/as de la UCR provenientes de las Sedes Regionales (izquierda) y los Recintos (derecha) para el periodo 2003-2011. En la actualidad la Sede Regional Limón se renombró como Sede Regional del Caribe. RdeGo= Recinto de Golfito; RdeP= Recinto de Paraíso y RdeG= Recinto de Guápiles

Se observa cómo la Sede Regional de Guanacaste es la que ocupa la primera posición por un margen de diferencia mínimo no significativo, lo que hace que sea prácticamente una posición compartida con las Sedes tanto de Occidente como del Atlántico. En el análisis que se 
detalló (Figura 8, margen derecho) en el caso del Recinto de Golfito, se infiere que su personal mantuvo lazos de colaboración muy cercana con contrapartes de las IES de Panamá, durante el periodo en estudio, ya sea en materia de investigación, proyectos de desarrollo tecnológico, transferencia de tecnología u otros programas de extensión o asuntos culturales varios.

\section{e. $\quad$ Programas de Becas Cortas y Becas de Posgrado en el Exterior}

La OAICE gestiona y supervisa la formación del personal docente y administrativo de la universidad propiciando la implementación de programas de alto nivel académico en el exterior. En este sentido el programa de becas de corta duración representa una oportunidad de capacitación de alto nivel para los profesores e investigadores y personal administrativo en servicio por periodos que van desde una semana hasta un máximo de un año.

Por otro lado, el Programa Institucional de Becas al Exterior (Ex-Becarios) de UCR otorga becas para que sus docentes o funcionarios administrativos realicen estudios de: doctorado, maestrías o especializaciones en el exterior.

\section{Tabla 4}

Programas de becas para Académicos y Administrativos hacia países de Centroamérica y algunos de la región del Caribe, periodo $2003-2011$

\begin{tabular}{|c|c|c|}
\hline \multirow{2}{*}{ AÑO } & \multicolumn{2}{|c|}{ BECAS } \\
\hline & $\begin{array}{c}\text { Corta } \\
\text { Duraciór }\end{array}$ & $\begin{array}{c}\text { Ex -Becarios } \\
\text { Estudios } \\
\text { Posgrado }\end{array}$ \\
\hline 2003 & 0 & 3 \\
\hline 2004 & 0 & 3 \\
\hline 2005 & 0 & 4 \\
\hline 2006 & 0 & 4 \\
\hline 2007 & 0 & 4 \\
\hline 2008 & 0 & 5 \\
\hline 2009 & 0 & 1 \\
\hline 2010 & 0 & 3 \\
\hline 2011 & 1 & 3 \\
\hline TOTAI & 1 & 30 \\
\hline
\end{tabular}

Nota: Elaboración propia de las autoras a partir de datos obtenidos de la OAICE de la UCR, 2013. 
Los resultados del programa de becas de corta duración para este periodo en la movilización de docentes nos indican que únicamente se registró una beca solicitada por la Escuela de Biología (Tabla 4) en el 2011 para realizar un curso de embriogénesis somática en especies tropicales en Cuba.

En el marco del Programa Institucional de Becas de Posgrado en el Exterior se realizaron 30 movilizaciones durante el periodo (Tabla 4), principalmente hacia Puerto Rico, Guatemala y Nicaragua. Estas becas concluyeron en estudios de doctorado (uno de Química y cuatro de Ciencias Sociales); Maestrías académicas (Ortodoncia, Investigación Clínica, Matemática aplicada) de las cuales una de las clínicas fue de tipo Posdoctoral y, una Especialización en ortodoncia.

Las Unidades Académicas de la UCR que se vieron favorecidas con estas becas fueron cuatro Escuelas: Química, Ciencias Políticas, Antropología y Sociología, la Facultad de Odontología y un profesor de la Sede de Occidente quien se preparó en Matemática aplicada.

\section{Acción 3. Movilidad Estudiantil}

En el ámbito de la movilidad estudiantil entrante y saliente, la UCR también ha facilitado la movilización de estudiantes hacia la UCR y de la UCR hacia el exterior, en el marco de convenios específicos de intercambio estudiantil.

En el período en estudio se desarrolló la movilidad estudiantil entrante a o saliente desde la UCR vs. IES centroamericanas y caribeñas, mediante la siguiente categorización: (a) Estudiantes visitantes de intercambio en la UCR vs. estudiantes de la UCR de intercambio en Centroamérica y el Caribe; (b) Estudiantes matriculados en grado en la UCR originarios de Centroamérica y el Caribe; (c) Estudiantes matriculados en el Sistema de Estudios de Posgrado de la UCR y (d) Estudiantes matriculados que participan en proyectos de Voluntariado de la Vicerrectoría de Vida Estudiantil.

\section{a. Estudiantes visitantes de intercambio en la UCR vs. estudiantes de la UCR de intercambio en Centroamérica y el Caribe}

En el período estudiado ha existido un marcado desequilibrio en la movilidad estudiantil desde y hacia la región centroamericana y caribeña que, de alguna manera, refleja lo que sucede de manera similar con otras regiones del mundo. En este caso para la región, la UCR recibe un número mayor de estudiantes, codificados como estudiantes matriculados visitantes, para un total de 41 de 2003 a 2011 y solamente envío en el 2004 a 8 estudiantes que escogieron ir hacia IES de Puerto Rico, en el marco de convenios de intercambio estudiantil.

De manera general, se puede indicar que los estudiantes recibidos en la UCR en periodo de intercambio estudiantil, durante este periodo, provenían en un 43,9\% desde Puerto Rico, le 
siguió en su orden descendente: Cuba con un 17\%; Honduras con 9,7\%; Guatemala, El Salvador y Panamá cada uno con $7,3 \%$ y los últimos países fueron Nicaragua $(4,9 \%)$ y Trinidad y Tobago $(2,4 \%)$.

\section{b. Estudiantes matriculados en grado en la UCR originarios de Centroamérica y el Caribe}

Los resultados para la Sede Central Rodrigo Facio (Figura 9) muestran un patrón repetitivo, constante y progresivo a lo largo del tiempo, donde independientemente del año, el mayor número de estudiantes matriculados se registra preferencialmente para estudiantes procedentes de Nicaragua.

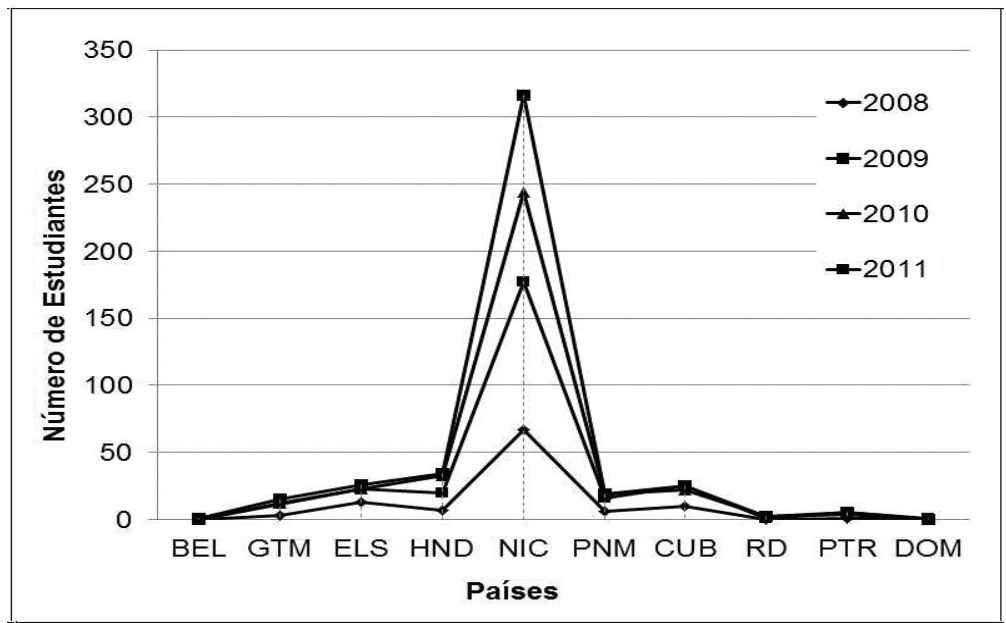

Nota: Elaboración propia de las autoras a partir de datos obtenidos de la Oficina de Registro e Información, Vicerrectoría de Vida Estudiantil de la UCR, 2013.

Figura 9. Estudiantes matriculados en grado y originarios de países de Centroamérica y Caribe para el periodo 2008 (II Ciclo) hasta 2011 en la Sede Central, Rodrigo Facio. BEL= Belice; GTM= Guatemala; ELS= El Salvador; $\mathrm{HND}=$ Honduras; $\mathrm{NIC}=$ Nicaragua; $\mathrm{PNM}=$ Panamá; $\mathrm{CUB}=\mathrm{Cuba}$ RD= República Dominicana; $\mathrm{PTR}=$ Puerto Rico y DOM= Dominica

Este mismo comportamiento de las matrículas de estudiantes de grado se reporta para las cinco Sedes de la UCR, incluyendo los Recintos de: San Ramón, Tacares, Turrialba, Paraíso, Guápiles, Liberia, Santa Cruz y Golfito. En todas las sedes excepto en la Sede de Occidente se reporta un incremento paulatino a lo largo del tiempo en la matrícula de los estudiantes de nacionalidad nicaragüense. En el caso de los estudiantes provenientes de otros países centroamericanos (Guatemala, El Salvador, Honduras y Panamá), por lo general, son ampliamente superadas por no menos de 25 o hasta 75 veces más por la matrícula de los estudiantes originarios de Nicaragua. 


\section{c. Estudiantes matriculados en el Sistema de Estudios de Posgrado de la UCR}

En el ámbito de posgrado un total de 531 centroamericanos y caribeños se han formado en la UCR de 2003 a 2011. En los programas de doctorado (Figura 10) se contabilizan 61 estudiantes matriculados mayoritariamente en posgrados de Educación, Historia, Ciencias, Gobierno y Políticas Públicas, de donde el 77\% lo cubren estudiantes procedentes de: Nicaragua (19), El Salvador (16) y de Panamá (12).

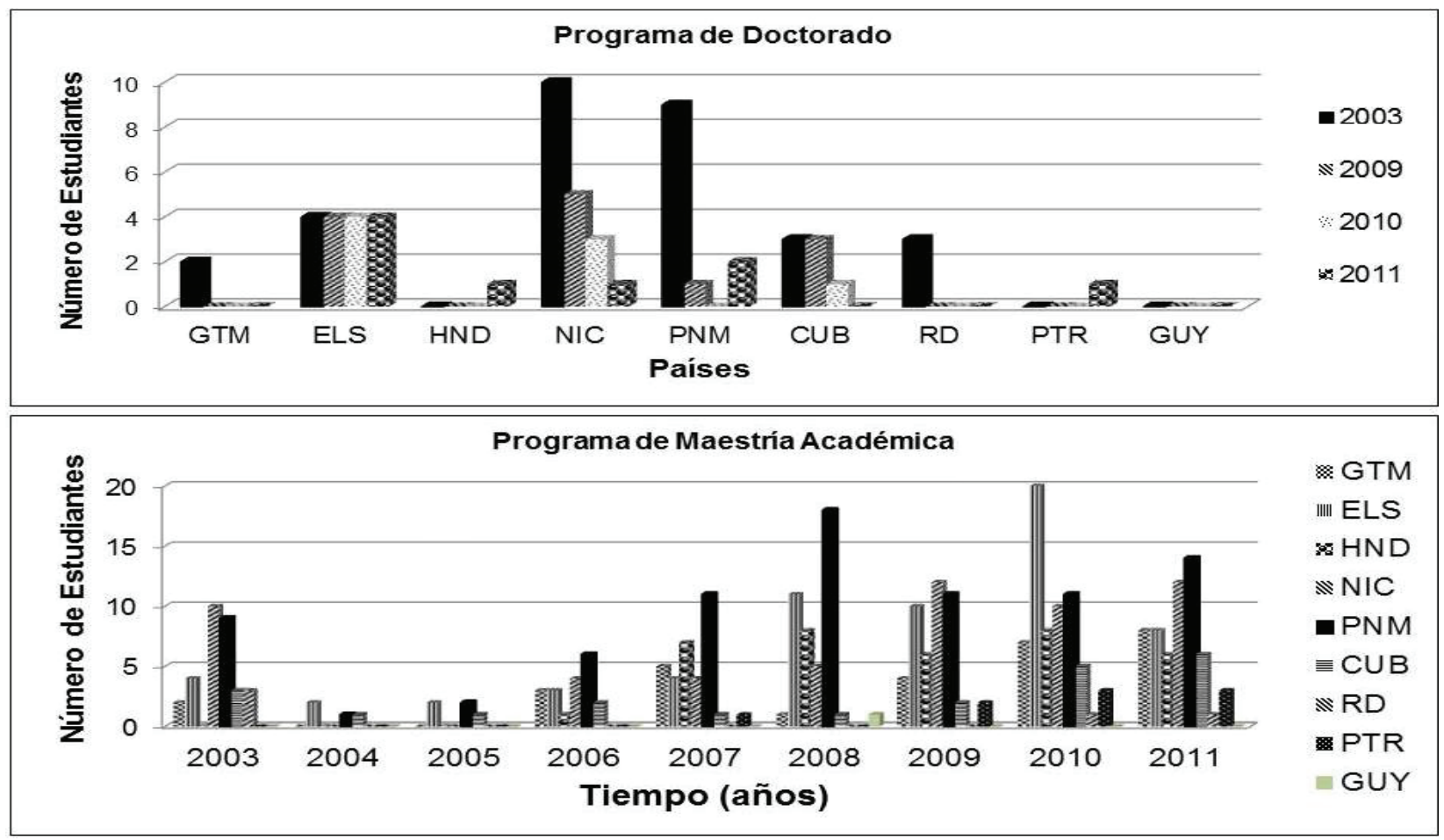

Nota: Elaboración propia de las autoras a partir de datos obtenidos de la oficina del SEP de la UCR, 2013.

Figura 10. Número de estudiantes de los programas de posgrado de Doctorado y Maestría Académica según procedencia desde los países de Centroamérica y algunos de la región del Caribe, periodo 20032011. $\mathrm{GTM}=$ Guatemala; $E L S=E l$ Salvador; $H N D=$ Honduras; $N I C=$ Nicaragua; $P N M=$ Panamá; $C U B=C u b a ; R D=$ República Dominicana; PTR= Puerto Rico y GUY= Guyana

Para el programa de Maestría Académica se reporta un total de 307 estudiantes matriculados principalmente en: Microbiología, Biología, Química, Geología, Hidrogeología, Historia, entre otras. La mayor afluencia de matrícula se dio a partir del 2007 hasta el 2011 con un incremento progresivo y sostenido; sobresale Panamá (83) con la más alta matrícula, le sigue de cerca El Salvador (64) y 
Nicaragua (57), pero en general se advierte que los programas de Maestría Académica de la UCR tienen alta preferencia por parte de los docentes e investigadores de la Región.

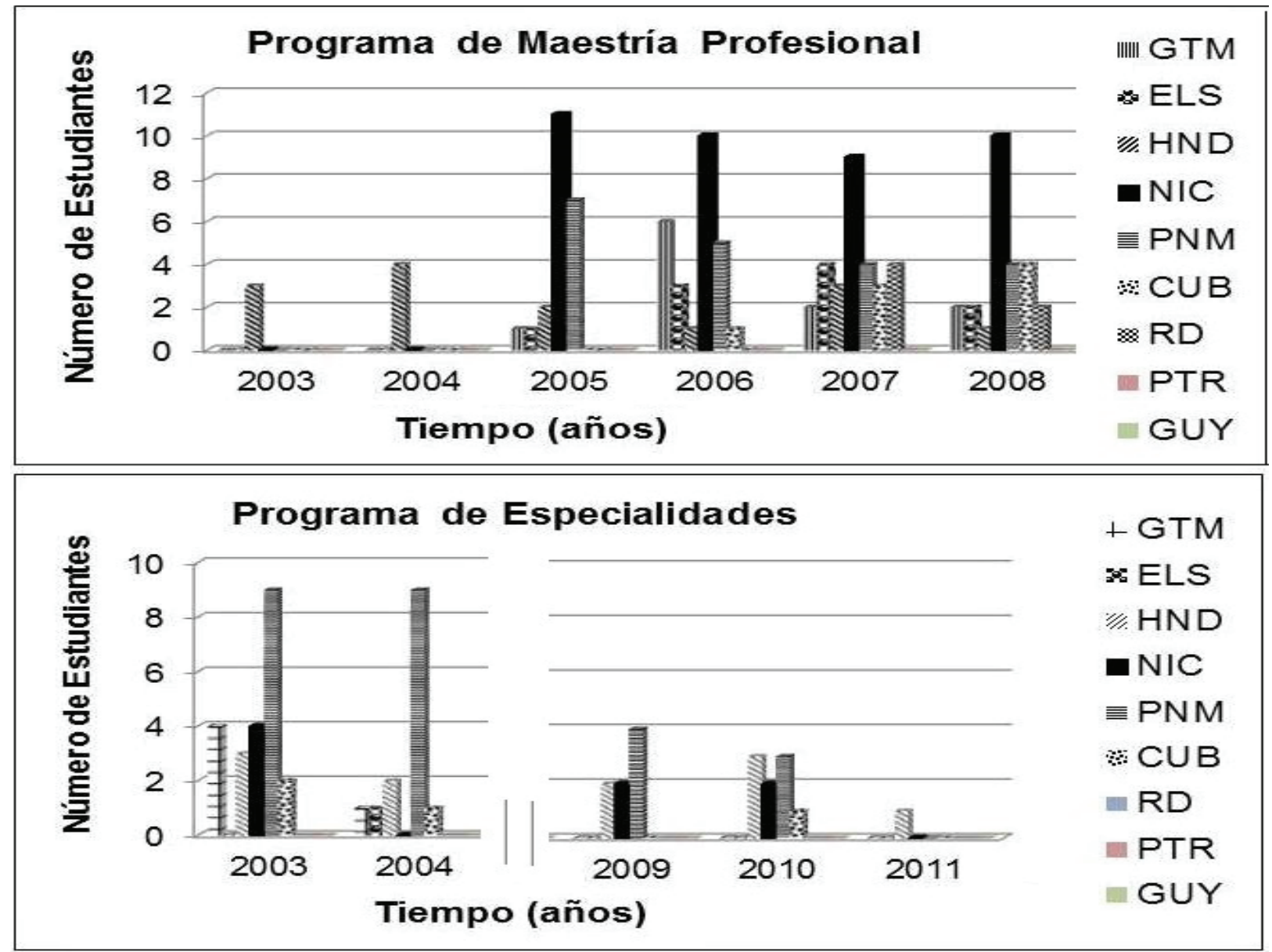

Nota: En Maestría Profesional, del 2009 al 2011 y en Programa de Especialidades, del 2005 al 2008, no se contó con la información. Elaboración propia de las autoras a partir de datos obtenidos de la oficina del SEP de la UCR, 2013.

Figura 11. Número de estudiantes de los programas de posgrado de Maestría Profesional y Especialidades según procedencia desde los países de Centroamérica y algunos del Caribe, periodo 2003-2011. GTM= Guatemala; $\mathrm{ELS}=\mathrm{El}$ Salvador; $\mathrm{HND}=$ Honduras; $\mathrm{NIC}=$ Nicaragua; $\mathrm{PNM}=$ Panamá; $\mathrm{CUB}=$ Cuba; $\mathrm{RD}=$ República Dominicana; PTR= Puerto Rico y GUY= Guyana

En el caso de los programas de Maestrías Profesionales se registraron 109 estudiantes en: Diplomacia, Odontología, Administración y Dirección de Empresas y Administración de la Construcción, principalmente. 
Resulta excepcional, de nuevo, identificar el mismo patrón de comportamiento en esta matrícula que la descrita anteriormente con la Maestría Académica (Figura 10) destacándose los países de la región con un 95\% del total de la matrícula y aquí es Nicaragua (40) la que aventaja con el $37 \%$ de cupos, le sigue Panamá (20), Honduras (14), Guatemala (11) y El Salvador (10) y el $5 \%$ restantes se distribuye en los países del Caribe.

Para las matrículas de los programas de Especialidades se empadronó un total de 54 estudiantes centroamericanos básicamente en el área de derecho y de la salud, entre otras.

En estos estudios la concentración de matrícula se dio en los años 2003 y 2004 y, de nuevo, se volvió a tener un número menor a partir del año 2009 al 2011 (Figura 11); no obstante, el patrón de matrícula es prácticamente el mismo: la preferencia se da desde los países de la región y, en este caso, es Panamá quien cuenta con la matrícula (25) mayor, le sigue Honduras (11); Nicaragua (8) y Guatemala (5) con estos hacen el $91 \%$ de la matrícula de estudiantes de posgrado provenientes de Centroamérica, el restante es para los países caribeños. Esta información global refleja que el porcentaje de matrícula para el periodo 2003- 2011 se distribuyó de acuerdo con los programas de la siguiente manera: Doctorado un 12\%; Maestría académica el 58\%; Maestría profesional el $20 \%$ y un $10 \%$ para las Especialidades.

En el período 2008 a 2011 un total de 16 estudiantes de los diferentes programas de posgrado de UCR participaron en congresos en países de la región centroamericana y caribeña, de los cuales 4 asistieron a congresos en Cuba, 3 en El Salvador, 3 en Honduras, 2 en Nicaragua y 1 en Panamá. El año de 2010 fue el que reveló el mayor porcentaje de participación.

\section{d. Estudiantes matriculados que participanen proyectos de Voluntariadodela Vicerrectoría de Vida Estudiantil}

El Programa de Voluntariado de la Vicerrectoría de Vida Estudiantil de la UCR aporta información sistematizada para cuatro años $(2004,2005,2006$ y 2007) consecutivos al periodo que contempla el presente estudio. Durante este tiempo el Programa de Voluntariado logró movilizar 15 estudiantes de la UCR a los siguientes países de la Región: Guatemala, Honduras y Nicaragua.

Los estudiantes movilizados en este programa lo hicieron principalmente a Honduras (7) distribuidos en el 2004 (2); 2005 (4) y 2006 (1), por lo general, ofrecieron capacitación al personal operativo de Informática en cuanto a la creación y diseño de páginas Web y sobre herramientas computacionales como Internet, y Office. Los tres estudiantes movilizados hacia Guatemala el 2005 (2) y el 2006 (1) apoyaron proyectos del PNUD dirigidos a asistir en técnicas de informática específicamente requeridas para dar seguimiento a contratos de forma acertada y eficiente. Asimismo, algunos estuvieron involucrados en actividades de los proyectos de dignificación y atención psicológica a víctimas del enfrentamiento armado en el marco del proyecto del PNUD. Los cinco estudiantes que se desplazaron a Nicaragua lo hicieron; tres para asistir, en el año 2005, al 
Primer Encuentro de Voluntarios Universitarios Centroamericanos y dos más recientemente, en 2007, participaron en la IV Reunión de la Red Latinoamericana de Voluntariado Estudiantil Universitario.

\section{Acción 4. Investigación}

Tradicionalmente, la UCR se ha posicionado en el ámbito nacional y regional como una institución líder en el área de investigación.

\section{Tabla 5}

Proyectos de Investigación ejecutados o en curso desarrollados por docentes e investigadores de la UCR en conjunto con investigadores de países de Centroamérica, periodo del 2003 al 2011

\begin{tabular}{|c|c|c|c|c|c|c|c|c|c|c|c|}
\hline Unidad & $\begin{array}{l}\text { Area Y } \\
\text { Académica }\end{array}$ & 2003 & 2004 & 2005 & 2006 & 2007 & 2008 & 2009 & 2010 & 2011 & TOTAL \\
\hline \multirow{3}{*}{ A2 } & CIBCM & 5 & 4 & 5 & 5 & 5 & 4 & 4 & 1 & 5 & \multirow{3}{*}{62} \\
\hline & CICA & 3 & 1 & 2 & 2 & 2 & 2 & 2 & 3 & 2 & \\
\hline & CIGEFI & 0 & 0 & 0 & 1 & 1 & 0 & 1 & 1 & 1 & \\
\hline \multirow{5}{*}{$\mathbf{A 3}$} & EADPUBL & 0 & 1 & 1 & 1 & 0 & 0 & 0 & 0 & 0 & \multirow{5}{*}{37} \\
\hline & ODD & 1 & 1 & 6 & 3 & 0 & 0 & 0 & 0 & o & \\
\hline & IICE & 0 & 0 & $\mathbf{0}$ & 0 & 2 & 1 & 2 & 2 & 2 & \\
\hline & us & 0 & 0 & 0 & 0 & 1 & 2 & 1 & 1 & 1 & \\
\hline & CCP & 0 & 0 & 0 & 0 & 1 & 1 & 1 & 3 & 2 & \\
\hline \multirow[b]{2}{*}{ A4 } & EINGCIV & 0 & 0 & 0 & 0 & 0 & 0 & 2 & 1 & 1 & \multirow[b]{2}{*}{7} \\
\hline & EINGAGR & 0 & 0 & 0 & 0 & 0 & 0 & 1 & 1 & 1 & \\
\hline \multirow{6}{*}{ A5 } & EMED & 1 & 0 & 0 & 0 & 0 & 0 & 0 & 0 & 0 & \multirow{6}{*}{20} \\
\hline & EENF & 0 & 0 & 0 & 1 & 2 & 1 & 0 & 0 & 0 & \\
\hline & SALUDP & 0 & 0 & 0 & 0 & 0 & 0 & 0 & 0 & 2 & \\
\hline & FACMICR & 0 & 0 & 0 & 0 & 0 & 0 & 0 & 0 & 1 & \\
\hline & ENUTR & 0 & 0 & 1 & 1 & 1 & 1 & 1 & 3 & 3 & \\
\hline & INIFAR & 0 & 0 & 0 & o & 0 & 1 & 0 & 0 & 0 & \\
\hline \multirow{5}{*}{ A6 } & CITA & 1 & 1 & 1 & 0 & 0 & 0 & 0 & 0 & 0 & \multirow{5}{*}{20} \\
\hline & EEAFBM & 0 & 1 & 1 & 1 & 1 & 1 & 1 & 1 & 2 & \\
\hline & CIA & 0 & 0 & 1 & 1 & 1 & 0 & 0 & 1 & 1 & \\
\hline & CIGRAS & 0 & 0 & 0 & 0 & 0 & 0 & 0 & 0 & 1 & \\
\hline & CIPROC & 0 & 0 & 0 & 0 & 0 & 0 & 0 & 0 & 2 & \\
\hline A9 & VINVEST & 0 & 1 & 1 & 1 & 0 & 0 & 1 & 1 & 0 & 5 \\
\hline
\end{tabular}

Nota: La clasificación se hace siguiendo el Sistema de Información de Proyectos de la Vicerrectoría de Investigación ${ }^{1}$ de la UCR. Elaboración propia de las autoras a partir de datos facilitados por la oficina del Sistema de Información de Proyectos de la Vicerrectoría de Investigación de la UCR, 2013.

La UCR en el período 2003-2011 contribuyó a fortalecer las capacidades de la región por medio de 151 proyectos de investigación inscritos en la Vicerrectoría de Investigación.

En la Tabla 5 se puede apreciar la variedad de áreas académicas en las que se han establecido proyectos de investigación. En este caso específico con la región, se determinaron únicamente 22 campos del saber y, los cuatro mencionados en el párrafo inmediatamente anterior como los más frecuentes, tienen en común las siguientes dos características: la sumatoria de sus acciones representan aproximadamente el 52\% de las actividades realizadas en materia de investigación 
durante el periodo y los investigadores que trabajaron en conjunto desarrollaron esfuerzos de investigación duraderos en el tiempo.

En los nueve años que cubre este estudio el Centro de Investigación en Biología Celular y Molecular (CIBCM) es la instancia que ha establecido un mayor número de proyectos (37), seguidamente el Centro de Investigación en Contaminación Ambiental (CICA) (19) y tanto la Escuela de Nutrición como el Observatorio del Desarrollo (OdD) han implementado (11) cada uno.

\section{Tabla 6}

Balance Global del número total de proyectos de investigación de la UCR referidos en términos de porcentaje de gestiones de investigación con Centroamérica, periodo 2003-2011. PI= Proyectos de Investigación. CA= Centroamérica

\begin{tabular}{|lccccccccccc|}
\hline \multicolumn{1}{|c}{ AÑO $\rightarrow$} & 2003 & 2004 & 2005 & 2006 & 2007 & $\mathbf{2 0 0 8}$ & $\mathbf{2 0 0 9}$ & $\mathbf{2 0 1 0}$ & $\mathbf{2 0 1 1}$ & TOTAL \\
\hline $\begin{array}{l}\text { Total PI Áreas con } \\
\text { CA }\end{array}$ & 11 & 10 & 19 & 17 & 17 & 14 & 17 & 19 & 27 & 151 \\
\hline $\begin{array}{l}\text { Gran Total Global } \\
\text { PI }\end{array}$ & 222 & 259 & 315 & 380 & 425 & 502 & 504 & 517 & 504 & 3628 \\
\hline $\begin{array}{l}\% \text { PIÁreas con } \\
\text { CA respecto } \\
\text { Gran Total PI }\end{array}$ & $4,9 \%$ & $3,9 \%$ & $6,0 \%$ & $4,5 \%$ & $4,0 \%$ & $2,8 \%$ & $3,4 \%$ & $3,7 \%$ & $5,4 \%$ & $4,2 \%$ \\
\hline
\end{tabular}

Nota: Elaboración propia de las autoras a partir de datos facilitados por la oficina del Sistema de Información de Proyectos de la Vicerrectoría de Investigación de la UCR, 2013.

En forma general se puede declarar que, durante el periodo en estudio, la UCR (Tabla 5) mantiene con la región un promedio de 16,8 proyectos por año frente a 403 aproximadamente que ejecuta con las demás zonas geográficas en el mundo (Tabla 6). Esta misma información permite evidenciar que únicamente con la región se mantiene un 4,2\% de relación en términos de investigación científica o de desarrollo tecnológico en comparación a lo que sucede con las otras zonas geográficas del mundo.

En el trabajo de la UCR con la región sobresalió el área de Ciencias Básicas con un total de 62 proyectos ejecutados durante el periodo en estudio, el área de Ciencias Sociales contó con 37 proyectos, las áreas de Salud y Ciencias Agroalimentarias desarrollaron 20 proyectos cada una, el área de Ingeniería y Arquitectura trabajaron con siete proyectos, mientras que la vicerrectoría de investigación mantuvo cinco acciones de seguimiento a proyectos con la región. 


\section{Acción 5. Reconocimientos}

Para el período en estudio la UCR ha valorado el trabajo realizado por destacados académicos de la región y ha otorgado reconocimientos a docentes, investigadores y estudiantes de la Institución que han impulsado el desarrollo de la región en diferentes ámbitos. Por ejemplo, el reconocimiento de Doctorado Honoris Causa, en el 2004, al Dr. Humberto López Morales de Cuba y en el 2009, al Dr. Augusto Elías Boneta de Puerto Rico.

Con el propósito de estimular el trabajo destacado del personal administrativo y proyectar una buena imagen de la UCR, se otorgan dos distinciones institucionales, a quienes se destacaron por su trabajo individual y colectivo. Por otro lado, en el periodo en estudio 2003-2011: 15 profesores e investigadores y 12 estudiantes de UCR recibieron distinciones y/o reconocimientos en alguno de los países de la región o del Caribe.

\section{Reflexión final}

Esta investigación pone en evidencia que en el proceso de internacionalización y cooperación académica de la UCR vs. IES centroamericanas y caribeñas se identifica una serie de buenas prácticas, tales como la participación en movilidades académicas y estudiantiles en el marco de convenios y programas de cooperación, proyección y fortalecimiento de programas de posgrado académico en la región; así como el intercambio académico y colaboración en el campo de la investigación.

Dentro de los principales avances encontrados en este estudio, se destaca que el proceso de internacionalización y cooperación académica internacional de la UCR con las IES de Centroamérica y el Caribe:

- Ha contribuido a mejorar la proyección de la UCR con respecto a otras universidades y dar seguimiento a compromisos internacionales derivados de las CMES y otros espacios regionales como el CSUCA que promueven la cooperación entre países en el tema de la educación superior, en todas sus dimensiones.

- Ha mantenido un número estable de convenios de cooperación vigentes en el periodo del 2003-2011, con pocas fluctuaciones. Asimismo, se constata una ligera tendencia por acuerdos de carácter específico sobre los de naturaleza general.

- Impulsa principalmente la movilidad académica entre UCR e IES de la región centroamericana y Caribe, con énfasis en intercambios cortos, en ambas direcciones.

- Favorece la movilidad de estudiantes de la región tanto a programas de grado como de posgrado, mediante la que se favorece el enriquecimiento académico, el intercambio de experiencias, la formación en valores de respeto a las otras culturas y se prioriza la oferta de cursos con perspectivas donde se aprovechan las competencias interculturales, para una preparación más integral de los estudiantes. 
- En lo referente a la acción de investigación de la UCR con la región se advierte un desempeño importante del área de Ciencias Básicas con un promedio de 6,9 proyectos en ejecución por año, para un total de 62 proyectos desarrollados durante el periodo en estudio. La participación de las siguientes áreas académicas, en su orden: Ciencias Sociales (37); Salud (20) y Ciencias Agroalimentarias (20); Ingeniería y Arquitectura (7) y otras (5) áreas, ha sido constante guardando su misma proporcionalidad en número de proyectos desarrollados a lo largo del tiempo (cuyo número se destaca entre paréntesis).

- Estimula el quehacer académico, técnico, científico o cultural que llevan a cabo docentes, investigadores, estudiantes o administrativos de la UCR con la región, así como reconoce a académicos o investigadores visitantes de altísima trayectoria provenientes de las IES de la región por sus aportes significativos que hacen a la educación superior regional.

Frente a estos hallazgos, se advierten también algunos retos a la gestión de la Internacionalización de la UCR con la región, que es importante tomar en consideración para orientar el planteamiento de estrategias que orienten el desarrollo y fortalecimiento de acciones de cooperación académica futura:

1. La política UCR de internacionalización dirigida a las IES centroamericanas y del Caribe, no es todavía una política integral por lo que la mayoría de las actividades realizadas se desarrollan con carácter disperso y muchos de los resultados generados no responden necesariamente a los objetivos estratégicos de la Institución.

2. La información relacionada con las actividades de internacionalización de UCR con las IES de Centroamérica y el Caribe no se encuentra debidamente sistematizada de manera particular ni accesible en la Web de UCR. Lo anterior afecta la visibilidad de las actividades como, por ejemplo, del impacto de proyectos conjuntos entre la UCR y universidades de la región.

3. Se requiere concientizar a la comunidad universitaria acerca de la importancia de fortalecer los vínculos de cooperación con universidades y otras instituciones centroamericanas y del Caribe, con el fin de valorar el potencial con el que estas cuentan.

\section{Referencias}

Calderón-Morales, C. (2013). Vinculación del Plan Estratégico Institucional 2013-2017 con las Políticas Institucionales 2010-2014. Oficina de Planificación Universitaria-OPLAU, Universidad de Costa Rica. San José, Costa Rica: UCR. 
Consejo Nacional de Rectores y Oficina de Planificación de la Educación Superior (CONAREOPES). (2005). Plan Nacional de la Educación Superior Universitaria Estatal 2006-2010 -PLANES 2006-2010. San José, Costa Rica: CONARE.

Consejo Nacional de Rectores y Oficina de Planificación de la Educación Superior (CONAREOPES). (2010). Plan Nacional de la Educación Superior Universitaria Estatal -PLANES 20112015. Recuperado de: http://www.conare.ac.cr/index.php/planificacion-institucional/ file/238-documento-planes-2011-2015.html

Cordón y Cordón, M. R. (2012). Proceso de armonización de la Educación Superior pública en la región centroamericana. Reconocimiento de estudios y títulos universitarios para el ejercicio profesional en Centroamérica. Recuperado de: http://www.observatoriorh.org/sites/ observatoriorh. org.centro/files/webfiles/fulltext/ta_resid2012/mrcordon_proceso.pdf

Declaración de La Sorbona. (1998). Declaración conjunta para la armonización del diseño del Sistema de Educación Superior Europeo. Recuperado de: http://www.ond.vlaanderen.be/ hogeronderwijs/bologna/links/language/1998_Sorbonne_Declaration_Spanish.pdf

Declaración de Bolonia. (1999). Declaración conjunta de los Ministros de Educación Europeos. Recuperado de: http://www.bologna-berlin2003.de/pdf/bologna_declaration.pdf

Días, M. A. (2008). La internacionalización y la cooperación interuniversitaria en la sociedad del conocimiento. En: C. Tünnermann (Ed.), La educación superior en América Latina y el Caribe: diez años después de la Conferencia Mundial de 1998. Colombia: Universidad Javeriana/UNESCO.

Fernández, N. (2012). La educación superior en América Latina. Aportes para la construcción de una nueva agenda. Revista Debate universitario, 1(1), 1-29. Recuperado de: http://ppct. caicyt.gov.ar/index.php/debate-universitario/article/view/1603

Gacel-Ávila, J. (2000). La dimensión internacional de las universidades mexicanas. Revista Educación Superior y Sociedad, 11(1-2), 121-142. Recuperado de: file:///C:/Users/ equipo\%201/Downloads/360-1270-1-PB.pdf

Instituto Internacional de la UNESCO para la Educación Superior en América Latina y el Caribe (IESALC-UNESCO). (2008). Declaración Final de la Conferencia Regional de Educación Superior en América Latina y El Caribe (CRES). Recuperado de: http://www.oei.es/salactsi/cres.htm 
Jensen-Pennington, H. (2015). Informe Anual 2013-2014. San José, Costa Rica: UCR.

Ministerio de Planificación Nacional y Política Económica (MIDEPLAN). (2010). Comportamiento de la cooperación internacional en Costa Rica: 2006-2008. Recuperado de: http:// documentos.mideplan.go.cr/alfresco/d/d/workspace/SpacesStore/07769661-9838-4610b200-86ad6b4f3c43/Comportamiento-cooperacion-CR-2006-2008-978-9977-73-049-3.pdf

Organización de las Naciones Unidas para la Educación, la Ciencia y la Cultura (UNESCO). (1998). Conferencia Mundial sobre la Educación Superior: La educación superior en el siglo XXI: Visión y acción. Recuperado de: http://www.unesco.org/education/educprog/wche/ declaration_spa.htm

Organización de las Naciones Unidas para la Educación, la Ciencia y la Cultura (UNESCO). (2009). Conferencia Mundial sobre la Educación Superior (CMES): La nueva dinámica de la educación superior y la investigación para el cambio social y el desarrollo. Recuperado de: http://www. unesco.org/education/WCHE2009/comunicado_es.pdf

Universidad de Costa Rica (UCR). (1972). Informe Rector 1971-1972. San José, Costa Rica: Autor.

Universidad de Costa Rica (UCR). (2012). Informe de Gestión Rectoría 2004-2012. Recuperado de: https://www.google.com/\#q=informe+gestion+ucr+2004-2012

Universidad de Costa Rica (UCR). (2008). Políticas de la Universidad de Costa Rica para los años 2010-2014. Gaceta Universitaria 40-2008 del 21-11-2008. Recuperado de: http://www. cu.ucr.ac.cr/normativ/politicas_institucionales_2010-2014.pdf

Universidad de Costa Rica (UCR). (2010). Reglamento para la asignación de recursos al personal universitario que participe en eventos internacionales. Gaceta Universitaria 7-2010 del 08/06/2010. Recuperado de: http://www.cu.ucr.ac.cr/normativ/asignacion_recursos.pdf

UniversidaddeCostaRicayOficinadePlanificaciónUniversitaria(UCR-PEI).(2008).PlandeDesarrollolnstitucional 2008-2012. Recuperado de http://oplau.ucr.ac.cr/index.php/plan-estrategico-institucional/plan-dedesarrollo-2008-2012/documento-plan-desarrollo-institucional/book/2?page=1

Universidad de Costa Rica y Oficina de Planificación Universitaria (UCR-PEI). (2013). Plan Estratégico Institucional 2013-2017. Recuperado de http://oplau.ucr.ac.cr/index.php/planestrategico-institucional/plan-estrategico-institucional-2013-2017 
Universidad Nacional Autónoma de Honduras (UNAH). (2004). Ley Orgánica UNAH. Recuperado de: https://vri.unah.edu.hn/acerca-del-vri/

Universidad Nacional Autónoma de Nicaragua (UNAN). (1996). Estatuto Orgánico. Recuperado de: http://www.unanleon.edu.ni/vicerrectoria relaciones externa.html

Zarur, X. (2008). Integración regional e internacionalización de la educación superior en América Latina y el Caribe. Recuperado de: http://www.clacso-posgrados.net/documentos_aportes/39.pdf 


\section{Anexo 1}

\section{Entrevista dirigida a la Coordinadora del Programa Regional, en el Centro de Información para Centroamérica de la DAAD}

Fecha: Miércoles, 23 setiembre de 2009

Hora: 10:00 A.M

Entrevistada: Coordinadora Programa Regional, Centro de Información para Centroamérica de la DAAD.

Lugar: Oficina de Becas del Servicio Alemán de Intercambio Académico (DAAD), en el CONARE, Edificio Franklin Chang, Pavas, Costa Rica.

La entrevista fue abierta y giró en torno a los Programas de Posgrado Centroamericanos, apoyados por la DAAD, en el desarrollo social, económico y cultural de la región. La coordinadora, habló acerca de la importancia de la existencia del Programa Regional de Posgrado, tanto en el ámbito de maestría como en doctorado y la valiosa experiencia científica de desarrollar un trabajo de tesis. Se trató de abordar la temática desde aspectos primarios hasta la visualización de estadísticas de los últimos años en cuanto a los logros alcanzados por el programa, con el fin de que esta información fuese de utilidad para este trabajo de graduación.

¿Cómo se originaron los Programas de Posgrado regionales de Centroamérica?

En la primera década de los años sesenta, con la iniciativa generada por los rectores de las universidades miembros del Consejo Superior Universitario Centroamericano (CSUCA), el Sistema de Carreras y Posgrados Regionales (SICAR), órgano encargado de apoyar, orientar y regular la oferta de carreras regionales de postgrado de las universidades miembros del CSUCA y el Programa Regional de Becas del Servicio Alemán de Intercambio Académico (DAAD) se propone la creación del Programa Regional de Posgrado. Los rectores de las universidades miembros del CSUCA, decidieron buscar una forma adecuada de ofertar programas regionales a nivel de posgrado en las diferentes universidades de la región, seleccionándose mediante criterios de pares académicos aquellas que tenían una capacidad instalada tanto en infraestructura como de recurso humano calificado en áreas específicas y que tuvieran el carácter de regional, para compartir recursos e intercambio de docentes. Así se instituyeron las carreras regionales para la formación de profesionales que Centroamérica necesitaba para su desarrollo.

¿Cuáles aspectos fueron determinantes para la estructuración del Programa?

Un elemento importante en el desarrollo de los programas de Posgrado regionales fue la iniciativa del Sr. Dietrich Genscher, Ministro de Relaciones Exteriores de Alemania, quien en 1985 crea el Programa Especial para la Promoción Académica de Centroamérica y Panamá. Con este Programa el Servicio Alemán de Intercambio Académico (DAAD) pretendía aportar a la formación de los recursos humanos en las universidades, fortalecer los posgrados regionales y promover la integración regional universitaria. El financiamiento del mismo procedía del Ministerio Federal de Cooperación Económica y Desarrollo de Alemania (BMZ). Hasta el año 2000 se otorgaron un promedio de 40 becas anuales nuevas. A partir de la firma de los acuerdos de paz en la región, el Programa Regional pasó, en el año 2000, a ser un programa regular y la cuota se redujo a 21 becas anuales. 
Los objetivos principales para establecer los programas regionales centroamericanos fueron:

- Mejorar la calidad académica de la enseñanza e investigación de las universidades centroamericanas.

- Capacitar los recursos humanos de las universidades de la región.

- Fortalecer los Posgrado de la región orientados al desarrollo.

- Contribuir a la creación de un espacio común regional para las universidades centroamericanas.

- Caracterizar aspectos personales y académicos de los egresados, condicionantes del programa.

- Identificar la influencia del programa regional en los procesos de desarrollo económico, social y cultural del país y de Centroamérica.

- Identificar las condiciones de reinserción laboral de los egresados.

- Identificar las motivaciones académicas iniciales del maestrante y su nivel de satisfacción profesional sobre el programa cursado.

- Analizar la pertinencia regional del programa en cuestión.

- Determinar el impacto del programa en el fortalecimiento de las universidades de origen y en la formación del graduado.

- Describir los aportes de los egresados al desarrollo científico, tecnológico, económico y sociocultural a nivel nacional y de la región centroamericana.

- Identificar los aportes del programa al desarrollo y crecimiento humano, profesional y laboral de los egresados.

- Analizar la participación de los egresados en el mejoramiento del programa.

- Determinar el impacto de la condición de becario o no becario en el proceso de formación académica del participante.

- Analizar la influencia de las becas del DAAD en el crecimiento y desarrollo del programa.

¿Cuáles han sido los antecedentes y la evolución en la región del Programa Regional, en el Centro de Información para Centroamérica de la DAAD?

El apoyo del DAAD a los Programas Regionales de Maestrías nació a mediados de la década de los 80, por iniciativa del entonces Decano del Sistema de Estudios de Posgrado de la Universidad de Costa Rica, Dr. Óscar Fernández, quien elevó la iniciativa al Ministerio de Planificación costarricense. Ante ello, el entonces Señor Presidente de la República Luis Alberto Monge Álvarez, en su segundo año de presidencia (1983) llevó la inquietud a los países de la Unión Europea, con el fin de obtener apoyo de becas para programas regionales del CSUCA y también para contar con profesores visitantes que reforzaran los programas de posgrado en la Universidad de Costa Rica. Esta solicitud contó con la acogida del entonces Ministro Alemán de Relaciones Exteriores Dietrich Genscher, quien la presentó al DAAD a finales de 1983. Las reflexiones giraban alrededor de la pregunta de si, por medio del apoyo alemán, un programa de ayuda para el mejoramiento de la educación en los países centroamericanos podría contribuir a aliviar las tensiones que la situación política y social habían causado en una región afectada por la crisis de la guerra. Ante ello, el Servicio Alemán de Intercambio Académico (DAAD) acogió la iniciativa y la transformó en un "Programa Especial para la Promoción Académica en Centroamérica" con fondos del Ministerio de Cooperación del Gobierno Alemán, con lo cual se empezaron a fortalecer los programas de posgrado regionales en el área centroamericana. 
La idea inicial era que, después de un período de haber iniciado el programa de becas, el CSUCA se involucrara en mayor grado en programas regionales y creara una estructura para facilitar la coordinación entre universidades en apoyo tanto a los procesos de becas como el intercambio docente, con el fin de consolidar así los programas regionales. (Zamora y Mackenbach, 2009). Esto, sin embargo es aún una tarea pendiente.

Las becas del DAAD fueron creadas como un programa especial para la promoción académica de Centroamérica y, en sus inicios, el número otorgado fue de alrededor de 40 por año. Sin embargo, después de 15 años, terminado el conflicto armado y con los avances del Plan de Paz en la región, el programa de becas se convirtió en un programa regular del DAAD. En el transcurso de su historia, el número de programas de posgrado aumentó, lo cual, unido a la característica de programa regular, ha provocado una disminución en la cantidad de becas otorgadas reduciéndose a 20 por año, preocupación expresada reiteradamente, por diferentes personas de los programas de maestría involucrados en este estudio.

¿Cuál ha sido la influencia regional del programa de becas del DAAD para la región?

EI DAAD ha jugado un papel sustancial, en el fortalecimiento académico, no existe otro programa igual en Centroamérica que haya incidido tanto en el fortalecimiento de la academia centroamericana. Se puede afirmar que en todas las universidades centroamericanas tenemos egresados del DAAD o que han recibido un apoyo sustancial para concluir sus estudios, principalmente en investigación científica.

El DAAD ha apoyado múltiples movilizaciones de estudiantes de programas de posgrado y ha facilitado el que se den formaciones en el campo de la Informática.

La coordinadora hace entrega de un listado impreso de cifras que muestran la evolución de los apoyos que ha dado la organización en la región e incluso información de becarios que se movilizan fuera de Costa Rica y de la región al mundo.

El DAAD reconoce que ha jugado un papel, estratégico en ciertas áreas, por ejemplo, señala el caso del área de Química, que atraviesa una situación delicada en varios países de Centroamérica, y manifiesta que se dio un apoyo enorme para que se reactivar programas en este capo del saber.

\section{(Footnotes)}

1 Según clasificación del Sistema de Información de Proyectos de la Vicerrectoría de Investigación las áreas (A) corresponden a: A2= Ciencias Básicas; $A 3=$ Ciencias Sociales; $A 4=$ Ingeniería y Arquitectura; $A 5=$ Salud; A6=Ciencias Agroalimentarias y A9= Otras Áreas. $\mathrm{CIBCM}=$ Centro de Investigación en Biología Celular y Molecular; $\mathrm{ClCA}=$ Centro de Investigación en Contaminación Ambiental; CIGEFI=Centro de Investigaciones Geofísicas; EADPUBL= Escuela de Administración Pública; OdD= Observatorio del Desarrollo; IICE= Instituto de Investigaciones en Ciencias Económicas; IIS= Instituto de Investigaciones Sociales; $\mathrm{CCP}=$ Centro Centroamericano de Población; EINGCIV=Escuela de Ingeniería Civil; EINGAGR= Escuela de Ingeniería Agrícola; EMED= Escuela de Medicina; EENEF=Escuela de Enfermería; SALUDP= Salud Pública; FACMICR=Facultad de Microbiología; ENUTR= Escuela de Nutrición; INIFAR= Instituto de Investigaciones Farmacéuticas; CITA= Centro Nacional de Ciencia y Tecnología de Alimentos; EEAFBM= Estación Experimental Agrícola Fabio Baudrit Moreno; $\mathrm{CIA}=$ Centro de Investigaciones Agronómicas; CIGRAS= Centro de Investigación en Granos y Semillas; $\mathrm{CIPROC}=$ Centro de Investigación en Protección de Cultivos y VINVEST= Vicerrectoría de Investigación. 